\title{
ACTITUDES HACIA LA DEMOCRACIA DE LAS ÉLITES PARLAMENTARIAS ARGENTINA Y PERUANA*
}

\author{
Flavia Freidenberg ${ }^{1}$
}

\section{INTRODUCCIÓN}

En las últimas décadas, muchos países latinoamericanos han experimentado profundas transformaciones a nivel político, económico y social. En el ámbito político, la revalorización de los principios democráticos y la adopción de un conjunto de instituciones han demostrado que era posible superar aquella dinámica de ciclos democráticosautoritarios que imposibilitó, durante mucho tiempo, el establecimiento de regímenes democráticos estables en la región ${ }^{2}$.

En la actualidad, el hecho de que se celebren elecciones competitivas periódicas y libres; se respete (en algún grado) la libertad de expresión y de asociación de los ciudadanos; se permita la presencia de grupos de oposición al gobierno y se deje participar a todos los actores en los asuntos políticos y, además, la información sea también transmitida por medios de comunicación independientes del poder político, entre muchos otros síntomas, parecieran indicar la vigencia de regímenes "poliárquicos" ${ }^{3}$ en algunos países de América Latina (O’Donnell; 1995).

Si bien algunos de los países de la región cumplen formalmente con los atributos indicados por Dahl (1971) como necesarios para que se alcance un régimen poliárquico; se presentan serias dificultades en el momento en que esos atributos (particularidades) se traducen en prácticas y comportamientos democráticos cotidianos. Las diferencias más significativas en este nivel se manifiestan en la concepción y en el significado de la democracia y, también, en el nivel e intensidad de implantación de la misma (Alcántara, 1997). Muchos gobiernos de países latinoamericanos dicen tener regímenes políticos "parecidos" a las democracias establecidas en otros rincones del planeta, pero carecen de algunos de sus atributos o, el contenido de esos atributos tienen precario sustento (O'Donnell; 1995).

Actualmente, uno de los problemas más significativos de la realidad socio-política latinoamericana tiene que ver con el tipo de reglas y comportamientos que dan sustancia a esos regímenes que se pretenden llamar democráticos. El problema ya no está vinculado con la inestabilidad del tipo de régimen sino con la calidad del régimen político que se está consolidando. Las prácticas políticas se van rutinizando; pero aún queda por comprender cual es su "contenido". En este sentido, se tiende a calificar a los regímenes políticos latinoamericanos como "democracias delegativas" (O’Donnell; 1992); "democracias en vías de consolidación" (Alcántara, 1995); "regímenes plebiscitarios" (Cotler, 1994) o como "democracias a medio camino" (Botana; 1997). Estas conceptualizaciones, en algún sentido, inten$\tan$ reflejar las dificultades que tienen las democracias latinoamericanas para consolidarse o, quizás, reflejen la naturaleza, tipo o calidad de los nuevos regímenes.

El estudio de las orientaciones políticas de las élites y de la ciudadanía es una línea de análisis desde donde es posible abordar el problema de la consolidación democrática (Diamond, 1993; Alcántara, 1997; Martínez; 1997;

* Una versión preliminar de esta ponencia fue presentada en el Encuentro Anual de Invierno del "New England Council of Latin American Studies" (NECLAS), en Mount Holyoke College, South Hadley, Massachusetts, Estados Unidos, el 18 de octubre de 1997.

1. Maestría en Estudios Latinoamericanos. Doctorado en "Procesos Políticos Contemporáneos". Instituto de Estudios de Iberoamérica y Portugal. Universidad de Salamanca.

Agradezco a Manuel Alcántara Sáez, David Scott Palmer, Iván Llamazares Valduvieco,Virginia García Beaudoux y Orlando D’Adamo los extensos comentarios y las acertadas sugerencias que le realizaron a este trabajo.

2. Entre 1977 y 1985, Ecuador, Perú, Bolivia, Uruguay, Argentina y Brasil vivieron procesos de transición desde regímenes autoritarios hacia otro tipos de regímenes (en algunos casos hacia "poliarquías institucionalizadas"; otros hacia "poliarquías de baja institucionalización" y algunos hacia nuevos tipos regímenes). A fines de la década del '80, Chile y Paraguay se unieron al grupo.

3. Desde que Dahl (1971) acuñó el concepto de "poliarquía”, para intentar definir a aquellos regímenes que sin ser autoritarios no llegaban a alcanzar el nivel de desarrollo democrático ideal; mucho se ha escrito sobre el tema. No es intención de este trabajo ahondar en una profunda discusión semántica y filosófica acerca de lo que realmente significa la democracia; solo queremos precisar que a los efectos del mismo utilizaremos el concepto de "poliarquía" o de "democracia política", en los tér minos precisados por O'Donnell (1995), para referirnos a los regímenes políticos actuales de América Latina. 
Alcántara y Llamazares, 1997; D’Adamo y García Beaudoux, 1995). En este sentido, Linz y Stepan (1997) consideran que una democracia tiene mayores posibilidades de consolidarse cuando un sector importante de las élites (políticas y económicas) y de la opinión pública creen que los procedimientos y las instituciones democráticas, aún en momentos de crisis económica o de desencanto con los líderes, son los más apropiados para gobernar la vida colectiva ${ }^{4}$. Estos estudios se sustentan en investigaciones como las desarrolladas por Almond y Verba (1963), donde se advertía la importancia de las creencias y las actitudes de los individuos hacia el proceso político en la estabilidad de un régimen democrático. Estas premisas suponen que tanto las creencias como los comportamientos que los individuos tengan hacia un régimen democrático contribuyen, en cierta medida, en el desarrollo, estabilidad y consolidación de ese tipo de régimen político.

En este sentido, no se debe confundir entre las reglas formales y las orientaciones políticas de las élites y de los ciudadanos. Puede que el significado y el contenido de esas reglas sean de un modo y que los individuos perciban un significado y un contenido distinto acerca de ellas y que, muchas veces, actúen de una manera distinta a las fijadas por esas reglas (comportamientos y, por tanto, reglas informales) ${ }^{5}$. Por eso es importante conocer las orientaciones políticas que los distintos grupos tienen acerca del régimen ${ }^{6}$. Y como el sentido de esas orientaciones en relación a la democracia puede presentar diversa intensidad; también el nivel de consolidación y la "calidad" que el régimen político presente puede ser diferente.

La élite política ${ }^{7}$ ejerce un papel significativo en el proceso de consolidación de la democracia, tanto por su influencia directa en el funcionamiento de las instituciones (como generadores de valores, creencias, símbolos, lenguajes y como intermediarios entre la sociedad y los diversos grupos sociales) y por el efecto que su comportamiento puede generar en otros estratos de la población ${ }^{8}$. Diversos autores (Burton, Higley y Gunther, 1991; Von Beyme, 1993) sostienen que un régimen democrático se consolida sólo cuando todas las élites de los grupos políticos aceptan las instituciones políticas existentes y se adhieren a las reglas de juego básicas del sistema político. Pero éste es un tipo ideal que no logra manifestarse en los hechos. Por ello, se puede complementar este esquema apelando a las ideas de Lamounier en relación a la consolidación democrática ${ }^{9}$, quién sostiene que este tipo de régimen político llega a consolidarse sólo cuando las reglas e instituciones democráticas son evaluadas por sí mismas, aún contra los resultados sustantivos adversos que éstas pueden generar a los intereses de las élites involucradas.

\section{ÉLITES Y PARLAMENTO}

Mucho se ha escrito sobre el papel del Parlamento en un régimen político democrático. El Parlamento es una de las instituciones políticas básicas dentro de este tipo de régimen (Spehar y Forti, 1995). En términos constituciona- les (y también en algún sentido ideales), esta institución ejerce múltiples funciones: de representación, legislación, control del poder ejecutivo y legitimación. Se presenta tanto como el escenario fundamental donde debatir ideas y programas; como la "caja de resonancia popular", lugar donde se reciben, amplían y debaten las demandas individuales y colectivas (Botinelli, 1995); o como el centro de representación y canalización de demandas de las distintas provincias o regiones.

A pesar de ello, en la historia democrática de América Latina, el papel del parlamento se ha visto eclipsado por la preeminencia del Poder Ejecutivo en el proceso de toma de decisiones, manifestado por ejemplo en la ampliación de las funciones legislativas del ejecutivo (Nolte; 1995). Los conflictos entre estos dos poderes han sido extensamente analizados por la literatura politológica (Nino, 1991; Nohlen y Fernández, 1991; Sartori,1994). De todos modos, más allá de estos conflictos y del predominio del presidente dentro del sistema político, no puede decirse que el Parlamento quede sin poder (Nolte; 1995) y que no sea importante estudiarlo.

Por el contrario, el estudio del Poder Legislativo y de sus miembros, la élite parlamentaria, es muy importante no solo por lo que ellos mismos significan sino también en el marco del proceso de consolidación democrática. Como mencionamos anteriormente, un régimen democrático estaría consolidado cuando todas las élites de los grupos

4. El régimen político se consolida cuando además de este tipo de actitudes; ningún actor político nacional, social, económico o institucional usa recursos significativos para lograr sus objetivos creando un régimen no-democrático (nivel de las conductas) y cuando los actores gubernamentales y no gubernamentales se han acostumbrado a solucionar los conflictos dentro de las leyes, los procedimientos y las instituciones sancionadas por el nuevo proceso democrático (nivel constitucional) (Linz y Stepan; 1997)

5. En cierto sentido esto es lo que O'Donnell (1995) ha denominado "particularismo" o "instituciones informales".

6. Sabemos de la importancia que tienen las creencias, los valores y las actitudes políticas de las élites y de la ciudadanía en el proceso de consolidación de la democracia y sabemos también de la importancia de sus comportamientos en dicho proceso; pero, a los efectos de este trabajo, sólo nos interesa analizar las orientaciones políticas hacia la democracia de la élite política.

7. A los efectos de este trabajo consideramos como miembros de la élite política a aquellas personas que ocupan cargos dentro de las instituciones políticas del sistema político y a aquellos otros, de estratos vagamente definidos de la sociedad, que hablan y actúan en roles políticos y que tienen poder e influencia.

8. Las orientaciones de la élite política dentro del sistema político son significativas por sí mismas y en relación a los demás grupos. Dah (1971) señala que esas orientaciones son importantes por tres razones: a) la élite política es más propensa a tener "sistemas de creencias políticas moderadas"; b) sus acciones tienden a ser guiadas por aquellas creencias y c) tienen más poder que otros actores y por tanto "más influencia sobre los eventos políticos, incluyendo eventos que afectan la estabilidad o transformación de los regímenes".

9. Distintos autores han reflexionado acerca de lo que se entiende por consolidación democrática, poniendo el énfasis en diversas cuestiones que van desde el proceso de estructuración e institucionalización de nuevo régimen (Morlino); la mera estabilidad del régimen (Huntington); la superación de enclaves autoritarios (Garretón); la existencia de una oposición electoral, que se presente como una alternativa real para la ciudadanía; el logro de la supremacía de la Sociedad Civil en el sistema democrático (Agüero y Piwonka y Torcal Loriente) 
políticos ${ }^{10}$ aceptan las instituciones políticas existentes y se adhieren a las reglas de juego acordadas.

Si suponemos que la presencia de determinados valores y creencias en la conducta de las élites políticas pueden colaborar en la persistencia del régimen democrático (Martínez, 1997); sólo nos queda estudiar las orientaciones políticas de esas élites en relación a ese régimen político. Sabemos que las élites políticas en América Latina no han sido profundamente estudiadas; que este es un campo de estudio que en ciertos aspectos aún está vacío y que nuestro desconocimiento sobre el tema es muy significativo (Alcántara y Llamazares; 1997). Por ello, consideramos interesante encarar este tipo de investigación, centrándonos en una serie de preguntas a las que intentaremos encontrarle algún tipo de respuesta: ¿Cómo son las orientaciones hacia la democracia de los diputados argentinos y peruanos? ¿Qué problemas perciben ellos para la consolidación de la democracia en su país?. En este sentido, el objetivo de este trabajo es presentar las opiniones de las élites parlamentarias argentina y peruana en torno a la democracia, sus principales ventajas (atributos) y las amenazas que ellos perciben para la consolidación del régimen político en su país.

\section{ARGENTINA Y PERÚ, DOS CASOS DE ESTUDIO}

Un conjunto importante de particularidades se presentan como marco justificatorio del análisis comparado de estos dos países. Una serie de similitudes pero, también, destacadas diferencias. En cuanto a las similitudes, además de una misma ubicación regional: América Latina; de un mismo pasado de dominación colonial: hispánico y de la preeminencia de un conjunto de creencias religiosas en su población: la católica; los sistemas políticos de ambos países comparten en el plano normativo particularidades que incluyen los principios republicanos; un carácter presidencialista de gobierno y una definición equivalente de las funciones de algunas de sus instituciones políticas; como el Congreso Nacional y los partidos políticos (aunque tan solo sea a nivel formal). Incluyendo un cierto estilo de hacer política en torno a la figura de un "hombre fuerte" que no reconoce la mediación de instituciones autónomas en su relación con las masas (Sanborn y Panfichi; 1996).

En el plano del funcionamiento del régimen político, ambos países vivieron en este siglo frecuentes golpes de estado cívico-militares que interrumpieron la vigencia democrática. En la década del 1980, estos países experimentaron momentos de cambio político orientados hacia la democracia (Perú, 1978 y Argentina, 1983). Una vez establecidos estos regímenes, el Poder Ejecutivo pasó a concentrar una mayor influencia en el proceso de toma de decisiones y fue quién asumió las responsabilidades "legislativas", relegando al Congreso Nacional a un segundo plano (Pásara, 1993a; Novaro, 1995).

Pero también las diferencias entre estos dos casos son significativas. Algunas de esas diferencias son simples detalles. Otras, son más profundas: particularidades culturales, económicas, étnicas y sociales que hacen necesario pensar la comparación entre estos países a partir de aquellas cosas que los separan.

Como punto de partida al analizar esas diferencias se deben tener en cuenta aspectos étnicos y económico-sociales de la sociedad peruana. La importante presencia indígena; la pobreza extrema de su población (para 1991, la mitad de sus ciudadanos se encontraba en un estado de pobreza crítica) y la profunda crisis económica de los últimos años (crisis sin comparación en América Latina) diferencian de manera significativa a este país andino de su homólogo del sur ${ }^{11}$.

La crisis económica erosionó la democracia peruana de distintas maneras: por una parte, dejando al Estado sin capacidad para proveer servicios ni para mantener a la burocracia (tanto a los empleados públicos como a los policías, soldados y jueces), siendo todos ellos más vulnerables al soborno y la extorsión (McClintock; 1996). Por otra parte, generando apatía política y desmovilización, ya que los trabajadores (temerosos de perder sus empleos) no participaban en los sindicatos ni en otro tipo de asociaciones propias de la sociedad civil. Además, el Perú vivía inmerso en un cruento clima de violencia política, caracterizado sobre todo por la expansión de la guerrilla (situación que no fue experimentada en la Argentina en esos años). Más de 30.000 personas han muerto por la violencia política en Perú desde 1980; se estiman alrededor de 5.000 desaparecidos y cerca de 20.000 millones de dólares en daños materiales (Palmer, 1994). Por estas y otras razones, en 1990, algunos expertos y la población en general creían que exitía la posibilidad de que el Estado peruano se derrumbase por su incapacidad de ejercer el monopolio legítimo de la coacción física (Kenney; 1996). Si bien Argentina también se vió inmersa en una profunda crisis económica, estatal y fiscal (García Delgado; 1995) que tuvo su punto de mayor inflexión en la crisis hiperinflacionaria de 1989; a partir del gobierno de Carlos Menem y la implementación de un modelo económico de caracter neoliberal ${ }^{12}$ algunas variables económicas comenzaron a estabilizarse (Nolte; 1995).

10. Si bien sabemos que no puede dibujarse una línea clara entre las élites políticas y todo lo demás (Higley; 1995); algunos autores (Almond, 1950; Fernádez Fontanoy, 1997) han distinguido dentro de la élite política una serie de subtipos. Creemos que es posible pensar que en aquellos regímenes democráticos que cuentan con sistemas de gobierno presidencialistas (como los latinoamericanos), la "élite política" puede ser analizada a partir de una serie de subgrupos que forman parte de ella pero que en su interior presentan particularidades diferenciadas: "élite gubernamental”, (por ejemplo: Presidente de la Nación); “élite parlamentaria”, (por ejemplo: Cámara de Senadores y Cámara de Diputados); "élite burocrática o administrativa", (por ejemplo: Miembros de los cuerpos profesionales del Estado); “élite de interés”, (por ejemplo: Miembros de grupos de presión o grupos de interés que pueden o no ocupar cargos formales dentro de instituciones); “élites partidarias", (por ejemplo: Miembros de los partidos políticos con participación dentro del sistema político).

11. Para 1989, el salario mínimo real peruano era el $23 \%$ de su valor en 1980; por debajo del $75 \%$ que era el promedio de la región (McClintock; 1996).

12. El plan económico consistió, en líneas generales, en establecer la convertibilidad de la moneda (paridad 1 a 1 del peso con el dólar estadounidense); la apertura de la economía y la liberalización de los precios; la privatización de las empresas públicas; la reducción del número de funcionarios públicos; la implementación de una rígida política fiscal; cierta flexibilización del sistema de seguridad social, entre otras políticas gubernamentales. 
Otra diferencia la encontramos en el modo en que se llevó a cabo la transición hacia la democracia en la década de 1980. Como señalamos anteriormente, los dos países vivieron procesos de cambio político; pero, mientras en Perú los militares y un sector de la élite política y económica acordaron una transición política negociada ${ }^{13}$ (Sanborn y Panfichi; 1996); en Argentina, esa transición no fue negociada sino que se dio por colapso (provocada —en partepor la fuga anticipada de poder que produjo la Guerra de Malvinas (1982) a la Junta Militar en el poder) (O’Donnell y Schmitter; 1986).

En relación al funcionamiento del régimen político, otra diferencia importante a tener en cuenta es que sólo desde 1980 se instaura de modo definitivo el sufragio universal en Perú. Es decir, que hasta ese momento sólo una minoría (de las élites) tenían acceso a las instituciones políticas; al ejercicio del poder y a la elección de los candidatos. Por su parte, Argentina incorporó el "sufragio universal" en 1912, posibilitando la participación de todos los ciudadanos (varones) en el sistema político. Finalmente, en la década de los cincuenta, con el gobierno peronista, se extendió el voto a la mujer.

En cuanto al objeto de nuestro trabajo, una diferencia importante es aquella vinculada a la legitimidad del régimen democrático. Mientras Argentina se ha caracterizado por la continuidad democrática y la vigencia de las instituciones democráticas, (aunque sea a nivel formal), sin ningún tipo de interrupción desde 1983; en Perú, en 1992, el Presidente Alberto Fujimori llevo a cabo un "autogolpe" ${ }^{14}$, que incluía un recetario de medidas como el cierre del Congreso Nacional, la deslegitimación de los partidos políticos, la suspensión de la vigencia de la Constitución de 1979, el arresto de algunos líderes de la oposición, la disolución de la Judicatura y el retraso de las elecciones municipales. El autogolpe y la violación a las libertades y los derechos humanos hacen imposible considerar hoy a Perú como una poliarquía (O'Donnell; 1995). En este sentido, observamos dos regímenes políticos cualitativamente distintos. Si bien en Argentina no funciona una democracia consolidada como la de los países desarrollados; al menos se da un "régimen competitivo, una democracia parcialmente liberal" (Hartlyn; 1994) o una "poliarquía de baja institucionalización” (O’Donnell; 1995). En el caso de Perú, mientras hay quienes consideran que ni siquiera puede denominarse "poliarquía", otros la llaman "democracia delegativa”(McClintock; 1996) y están quienes consideran que es un régimen "autoritario" (Hartlyn; 1994).

El modo en que se realizaron las reformas constitucionales (en 1994), en cada uno de estos países, también fue distinta. En Argentina, esa reforma fue posible a partir de un acuerdo entre los dos partidos tradicionales (y mayoritarios) de ese momento, el Justiciadista y la Unión Cívica Radical, quienes con el "Pacto de Olivos" establecieron un Núcleo de Coincidencias Básicas, a partir del cual se determinó aquello que iba a ser reformado de la Constitución de 1853. Una vez reunida la Asamblea Constituyente en Santa $\mathrm{Fe}$, las discusiones se centraron principalmente en ese conjunto de cuestiones acordadas de antemano por esos dos partidos ${ }^{15}$. En el caso de Perú, la reforma de la Constitución de 1979 se produjo de manera casi unilateral, a raíz del autogolpe y de la presión internacional (Estados Unidos, la Organización de Estados Americanos) por el restablecimiento de las instituciones democráticas. Para las elecciones de los candidatos del Congreso Constituyente Democrático (CCD), el gobierno de Fujimori estableció reglas de juego especiales ${ }^{16}$ y actuó, en cierto sentido, de manera poco clara, tanto que hace pensar en la manipulación del proceso electoral (McClintock; 1996).

En cuanto al Poder Legislativo estos países presentan distintos tipos de organización, a raíz de las modificaciones que se produjeron en la Constitución de Perú. En Argentina, tras la reforma constitucional, continúa vigente el sistema bicameral: una Cámara de Diputados (257 miembros) y una Cámara de Senadores de la Nación (72 miembros). En tanto, en Perú, la organización pasó a ser unicameral y el Congreso de la República cuenta con 120 representantes.

Otro de los rasgos diferenciadores importantes lo encontramos en el sistema de partidos, dado que en Argentina se ha delineado en los últimos tiempos un sistema bipartidista (con cierta tendencia de partido predominante); y con ausencia de perfiles programáticos nítidos que diferencien una alternativa partidaria de otra. Estas características se vieron reforzadas en los últimos meses por la alianza concertada entre la Unión Cívica Radical y el Frente País Solidario que reubicó estratégicamente a los distintos actores partidarios. En el caso de Perú, el sistema de partidos es multipartidista, con una oferta partidaria diversificada que permite identificar con cierta nitidez opciones de derecha, centro e izquierda. Además, en este país es posible encontrar aún grupos antisistemas y agrupaciones no partidarias (o líderes antipolíticos) que triun-

13. A cambio de posibilitar un retorno gradual a la democracia, los militares recibieron garantías de que mantendrían intactas las bases de su poder. Esto les permitió seguir ejerciendo su capacidad de veto y mantenerse dentro del escenario político como actores estratégicos (enclaves autoritarios). En cambio, en Argentina, los militares perdieron todo su poder y no pudieron ni siquiera "negociar" la transición (en 1985, los miembros de la Junta Militar fueron juzgados y condenados por un Tribunal Civil.Y, a pesar de que luego fueron indultados por el gobierno de Menem, nunca recuperaron su capacidad de veto ni se convirtieron en actores estratégicos).

14. Fujimori, que había sido electo veinte meses antes, fue apoyado por los oficiales militares, las élites económicas y por casi el $80 \%$ de la población según los sondeos de opinión. Sin embargo, diversos autores (Tuesta Soldevilla, 1994; Conaghan, 1995), advierten sobre la interpretación de este tipo de encuestas en Perú, dado que se tiende a sobrepresentar al sector urbano de las clases medias y sub-representar al sector indígena (CFR: McClintock; 1996).

15. Para un estudio acerca de la Reforma Constitucional en Argentina ver Nolte (1995).

16. Entre esas medidas se encuentran la destitución del dirigente del Jurado Nacional Electoral (JNE); la obligación de recolectar 100.000 firmas a los partidos nuevos y a aquellos que habían recibido menos del $5 \%$ de los votos en las elecciones previas para poder competir en los comicios; la ubicación privilegiada de NM-C'90 en las papeletas de votación; la escasez de oficiales de monitoreo en las mesas de votación; el poco tiempo de campaña electoral (dos semanas), cuando la mayoría de las agrupaciones políticas eran casi desconocidas para la población (McClintock; 1996). 
COMPOSICIÓN DE LA CÁMARA DE DIPUTADOS ARGENTINA ${ }^{18}$

\begin{tabular}{l|c|c|c|c}
\hline Partido Político & Bancas & $\begin{array}{c}\text { Cantidad } \\
\text { entrevistada }\end{array}$ & $\begin{array}{c}\text { Porcentaje } \\
\text { de bancas }\end{array}$ & $\begin{array}{c}\text { Porcentaje } \\
\text { entrevistas }\end{array}$ \\
\hline Partido Justicialista (PJ) & 131 & 23 & $51 \%$ & $34 \%$ \\
\hline Unión Cívica Radical (UCR) & 68 & 19 & 26 & 28 \\
\hline Frente País Solidario (FREPASO) & 23 & 12 & 9 & 18 \\
\hline Otros $^{19}$ & 35 & $14^{20}$ & 13 & 20 \\
\hline Total & 257 & 68 & 100 & 100 \\
\hline
\end{tabular}

Fuente: Revista Noticias, 28/10/97 y Base de datos: Élites Parlamentarias de América Latina. Elaboración: la autora

COMPOSICIÓN DE LA CÁMARA DE DIPUTADOS PERUANA:

\begin{tabular}{l|c|c|c|c}
\hline Partido Político & Bancas & $\begin{array}{c}\text { Cantidad } \\
\text { entrevistada }\end{array}$ & $\begin{array}{c}\text { Porcentaje } \\
\text { de bancas }\end{array}$ & $\begin{array}{c}\text { Porcentaje } \\
\text { entrevistas }\end{array}$ \\
\hline Nueva Mayoría/Cambio'90 (NM/C'90) & 67 & 52 & $56 \%$ & $60 \%$ \\
\hline Unión por el Perú (UPP) & 17 & 12 & 14 & 14 \\
\hline Alianza Popular Revolucionaria Americana (APRA) & 8 & 7 & 7 & 8 \\
\hline Otros $^{21}$ & 28 & $16^{22}$ & 23 & 18 \\
\hline Total & 120 & 87 & 100 & 100 \\
\hline
\end{tabular}

Fuente: Kenney (1996) y Base de datos: Élites Parlamentarias de América Latina. Elaboración: la autora

fan electoralmente y luego gobiernan, sin necesidad de estructuras partidarias, como es el caso del actual presidente peruano. Según Mainwaring y Scully (1997), Argentina cuenta con un sistema de partidos competitivos institucionalizados mientras que el caso de Perú debe considerarse como un sistema de partidos menos institucionalizado o incipiente.

\section{METODOLOGÍA}

Las encuestas realizadas en el marco del proyecto Elites Parlamentarias en América Latina, financiado por la Comisión Interministerial de Ciencia y Tecnología (SEC95-0845) y dirigido por Manuel Alcántara Sáez, constituyen el sustento empírico de este trabajo.

Esta investigación se llevó a cabo en 18 países latinoamericanos. La misma consistió en entrevistar a los legisladores y preguntarles sus opiniones sobre inestabilidad política y consolidación democrática; sistema electoral; régimen de gobierno; relaciones entre el legislativo-ejecutivo; papel del Estado en la economía; política económica; problemas nacionales; política exterior; partidos políticos; movimientos sociales; fuerzas armadas; subversión; derechos humanos; la política como profesión; religión e historias personales de los legisladores.

En Argentina se administró el cuestionario de 104 preguntas a $68^{17}$ diputados, entre junio de 1996 y julio de 1997, y en Perú se entrevistó a 87 diputados peruanos entre octubre y diciembre de 1995.

\section{PRESENTACIÓN DE LOS RESULTADOS Y ANÁLISIS DE LOS DATOS ${ }^{23}$}

\section{Valoración de la democracia como sistema preferible:}

La valoración de la democracia como escenario imprescindible en el que se desarrolla la vida política es sustancial para la institucionalización de los conflictos (Alcántara, 1995). Mientras más alto sea el compromiso

17. Cerca de cincuenta diputados argentinos se negaron a concertar entrevistas con miembros del equipo de trabajo argumentando motivos personales, laborales y, (en un mayor número), manifestando su desconfianza acerca de la cientificidad de este tipo de investigaciones en ciencias sociales.

18. Esta composición partidaria estuvo vigente en el período 1995. 1997. No incluye las modificaciones producidas por los comicios del 26 de octubre de 1997; a partir del cual se renovó la mitad de los miembros de la Cámara de Diputados de la Nación.

19. No se pudieron obtener datos precisos acerca de la composición partidaria de la Cámara de Diputados. A los efectos de esta presentación se consultaron distintas fuentes (Datos Provisorios Elecciones'95 del Ministerio del Interior, Informe UBA-Clarín para las elecciones de 1995 en Internet; Political Database of Latin America en Internet, Revista Noticias del 2-11-97) y todas ellas presentaban datos diferentes.

20. La distribución por partidos de la muestra es la siguiente: UCeDé: 3; PAIS: 2; MPN, 2; Demócrata de Mendoza: 2; Demócrata Progresista, 1; FR, 1; AC., 1; Renovador de Salta, 1; MODIN, 1; Nueva Dirigencia:1.

21. En la categoría "otros" se incluye al resto de los partidos políticos con representación parlamentaria: Frente Independiente Moralizador (FIM); 6 bancas; CODE-País Posible (PP), 5 bancas; Acción Popular (AP), 4 bancas; Partido Popular Cristiano (PPC), 3 bancas: Renovación, 3 bancas; Izquierda Unida (IU), 2 bancas; Mov. Obras, 2 bancas; Perú al 2000-Frena Traca (FNTC), 1 banca; Frente Popular Agrícola (FPA), 1 banca, Mov. Independiente Agrario (MIA), 1 banca.

22. La distribución por partidos es la siguiente: FIM: 2; Acción Popular: 3; PCC: 1; Renovación: 3; Mov. Obras: 1; IU: 2; CODE: 2; FNTC: 1 ; MIA:1. 
de los individuos (en número e intensidad) con la legitimidad de ese régimen, mayor será la capacidad de éste para sobrevivir a crisis serias de eficacia y efectividad al enfrentarse con los problemas que se le presenten (Linz, 1989). Cuanto mayor sea el apoyo que la élite política (y la ciudadanía) manifiesten hacia la democracia mayores serán las posibilidades que ésta tenga para consolidarse. En este sentido, la creencia que cada uno tenga acerca del sistema político existente es fundamental. Uno se convierte en demócrata cuando prefiere a la democracia frente a cualquier otro sistema: cuando cree que éste es el mejor sistema en el que podría vivir. Y esta creencia hacen de uno un "demócrata incondicional" ${ }^{24}$ (Maravall, 1996).

En el Cuadro $\mathrm{N}^{\circ} 1$, podemos observar los datos proporcionados por la investigación de "Élites Parlamentarias en América Latina", donde los diputados argentinos consultados $(97 \%)$ consideraron que, en contextos de crisis económica e inestabilidad política en que a un sistema político se le plantea la toma de importantes decisiones, la democracia es siempre el mejor sistema político para un país. En el caso de Perú, 69 legisladores peruanos (79\%) coincidieron con la opinión de los argentinos pero 13 de ellos (15\%) manifestaron estar más o menos de acuerdo con que la democracia sea siempre el mejor sistema político y el $6 \%$ restante se posicionó (en diferentes niveles) en desacuerdo con dicha afirmación.

\section{CUADRO N ${ }^{\circ} 1$}

Valoración hacia la democracia como sistema político $(\%)^{25}$

\begin{tabular}{l|c|c}
\hline & Argentina & Perú \\
\hline Muy de acuerdo & 97 & 79 \\
\hline Más o menos de acuerdo & 3 & 15 \\
\hline Más o menos en desacuerdo & 0 & 5 \\
\hline Muy en desacuerdo & 0 & 1 \\
\hline Total & 100 & 100 \\
\hline $\mathrm{n}$ & 68 & 87 \\
\hline
\end{tabular}

Fuente: Investigación Élites Parlamentarias en América Latina

Para comprender la acción política de los parlamentarios es importante conocer cómo ellos perciben e interpretan su propia posición, sus finalidades y su entorno (Alcántara y Llamazares, 1997). Si hay sectores importantes de las élites que dudan o desestiman a la democracia como sistema político, aún en momentos de crisis económica, inestabilidad política o desencanto con sus líderes, las posibilidades de que el sistema democrático se consolide son escasas (Linz y Stepan; 1997).

Los resultados obtenidos en el caso argentino muestran una particular homogeneización y una extensión general de apoyo a los valores democráticos. En este sentido, se podría considerar a la élite parlamentaria argentina de la muestra como "demócrata" ${ }^{26}$. Y podríamos arriesgarnos un poco más y decir que, en caso de que se le presentasen dificultades al sistema político, la élite parlamentaria de este país defendería las instituciones y los procedimientos democráticos ante cualquier otra alternativa ${ }^{27}$. En tanto, cerca del $21 \%$ de los legisladores peruanos dudan y hasta se manifiestan en desacuerdo con que la democracia sea siempre el mejor sistema político para su país. Esto perjudica la consolidación del régimen político peruano que, como mencionamos anteriormente, ni siquiera cumple los atributos de una poliarquía (O’Donnell; 1995) y genera cierto tipo de sospechas acerca de la actitud que podría llegar a tener la élite parlamentaria peruana si se les presentara la necesidad de defender la democracia. En este sentido, no habría más que analizar cual fue la actitud de los diputados peruanos en el momento de defender los procedimientos y las instituciones democráticas ante el autogolpe de 1992.

Pero, ¿a qué partido político pertenecen esos diputados peruanos que dudaron de la democracia como mejor sistema político?

\section{CUADRO N ${ }^{\circ} 2$}

Valoración hacia la democracia como sistema político por partido político $(\%)$

\begin{tabular}{l|c|r|r|c}
\hline & NM/C'90 & UPP & APRA & OTROS \\
\hline Muy de acuerdo & 71 & 92 & 100 & 87 \\
\hline $\begin{array}{l}\text { Más o menos } \\
\text { de acuerdo }\end{array}$ & 21 & 0 & 0 & 13 \\
\hline $\begin{array}{l}\text { Más o menos } \\
\text { en desacuerdo }\end{array}$ & 6 & 8 & 0 & 0 \\
\hline Muy en desacuerdo & 2 & 0 & 0 & 0 \\
\hline Total & 100 & 100 & 100 & 100 \\
\hline $\mathrm{n}$ & 52 & 12 & 7 & 16 \\
\hline
\end{tabular}

Fuente: Investigación Élites Parlamentarias en América Latina

23. Los porcentajes presentados fueron calculados excluyendo aquellos legisladores que no quisieron responder o que argumentaron no saber la respuesta.

24. Maravall utiliza la categoría "demócrata incondicional” para calificar a aquellos que manifiestan su acuerdo con la siguiente afirmación: "La democracia es siempre preferible como régimen político". A aquellos que consideran que "El autoritarismo es preferible en ciertas condiciones..." se los agrupa en "autoritarios condicionales". Mientras quienes sostienen que les resulta similar vivir en un tipo de régimen como en otro los incluye en la categoría de “indiferentes".

25. La pregunta que se administró a los encuestados fue la siguiente: "En contextos de crisis económica e inestabilidad política en que a un sistema político se le plantea la toma de importantes decisiones, ¿estaría Usted de acuerdo con la afirmación de que la democracia es siempre e mejor sistema político para un país?. Elija una de estas opciones:" Respuesta: muy de acuerdo - más o menos de acuerdo - más o menos en desacuerdo - muy en desacuerdo - no sabe - no contesta.

26. Por lo menos, en los términos expuestos por Maravall (1996).

27. Sería interesante analizar las razones de esa defensa de la democracia por la élite parlamentaria argentina, a la luz de la experiencia vivida por este país en los últimos años. Por el momento, esta cuestión excede el marco del presente trabajo, pero es una de las tantas cuestiones que quedan a la espera de ser profundizadas. 
Los resultados muestran que aquellos que dudan de la democracia son, en su mayoría, legisladores de la agrupación NM/C'90, que actualmente gobierna en Perú. Cerca del $30 \%$ de los diputados del oficialismo desestimaron a la democracia como mejor sistema político; ningún diputado del APRA dudó acerca de la legitimidad de la democracia y sólo uno de UPP se manifestó por estar más o menos en desacuerdo con que la democracia sea siempre el mejor sistema político para el país ${ }^{28}$.

Los hechos también avanzan en este sentido. Cuando Perú se enfrentó a decisiones importantes (en relación a la crisis económica y al clima de violencia política,por ejemplo) el presidente Fujimori, (junto a los miembros del gobierno y a la agrupación que lo llevó al poder), decidió suprimir la vigencia de los procedimientos e instituciones democráticas. Estos legisladores oficialistas, en algun sentido, legitimaron la "deslegitimación" del sistema democrático. Quien no cree en la democracia no puede crearla, mantenerla o refundarla (pero quizás pueda llegar en algún momento a aceptarla). Y parece ser que algunos legisladores de NM/C'90, que forman parte de la muestra, no son "demócratas incondicionales" ni en sus creencias ni en sus comportamientos.

Más allá de las conceptualizaciones expuestas, algunos autores (Maravall, 1996) sostienen que no sólo la legitimidad que el régimen posea es importante para la consolidación democrática ${ }^{29}$. Adicionalmente se hipotetiza que para que una democracia se consolide, además de ser percibida como legítima, tienen importancia los resultados que a partir de ella se generen ${ }^{30}$.

\section{Los peligros de la democracia}

Si en un primer momento se le preguntó a los legisladores acerca de su percepción sobre la democracia en términos ideales; el siguiente paso consistió en consultarlos acerca de los peligros que puede generar este régimen político. En el Cuadro $\mathrm{N}^{\circ} 3$, podemos observar que ningún parlamentario argentino considera que la democracia sea peligrosa porque puede generar inestabilidad política y social; mientras que cerca de un $18 \%$ de legisladores peruanos si consideran que la democracia es peligrosa, el

\section{CUADRO N³}

Valoración de la democracia como fuente de desorden $(\%)^{31}$

\begin{tabular}{l|c|c}
\hline & Argentina & Perú \\
\hline Muy de acuerdo & 0 & 5 \\
\hline Más o menos de acuerdo & 0 & 13 \\
\hline Más o menos en desacuerdo & 3 & 16 \\
\hline Muy en desacuerdo & 97 & 66 \\
\hline Total & 100 & 100 \\
\hline $\mathrm{n}$ & 68 & 85 \\
\hline
\end{tabular}

Fuente: Investigación Élites Parlamentarias en América Latina
$16 \%$ dudó al respecto y, tan solo el $66 \%$ de los entrevistados se manifestó tajantemente en desacuerdo con esta afirmación.

Mientras la mayoría de los legisladores argentinos de la muestra (97\%) consideraron que la democracia no es fuente de desorden y desorganización; hubo un porcentaje importante de legisladores peruanos $(34 \%)$ que desconfiaron (en algún nivel) de la democracia y que consideraron que este régimen político puede llegar a ser peligroso. Para interpretar estos datos se debe tener en cuenta el clima de violencia política en el que se vio inmerso este país en los últimos años, que no disminuyó una vez que se reinstauraron las instituciones políticas democráticas. En los años 1990 y 1991, cerca de 750 personas desaparecieron en manos de las fuerzas de seguridad peruanas. Según un Informe del Comité Nacional de Coordinación en Derechos Humanos del Perú, para 1992, este país era el que tenía peor récord en derechos humanos en el hemisferio occidental. Por otra parte, entre 1988 y agosto de 1992 , más de 400 líderes políticos murieron en manos de la guerrilla (McClintock; 1996). El clima de violencia persistió, entonces, bajo un régimen democrático. De este modo podemos intuir que las percepciones hacia la naturaleza del régimen político estarían influenciadas por el contexto socio-político propio de cada uno de los países; la experiencia vivida por esos individuos y la memoria histórica que tienen acerca de los acontecimientos.

28. Es importante precisar algunos datos contextuales a los efectos de comprender estos resultados. Los legisladores consultados son los mismos diputados que asumieron en sus cargos en las elecciones de 1995, luego del autogolpe de 1992, cuando Fujimori cerró el Congreso Nacional. Es importante tener en cuenta, también, que durante el período 1990-1992, Cambio '90 contaba sólo con 32 escaños (el 18\%) de la Cámara de Diputados y que Fujimori necesitaba el apoyo de por lo menos 59 bancas más para alcanzar la mayoría. Una vez realizadas las elecciones de 1995, Cambio '90 alcanzó 67 escaños, más del doble de los diputados que tenían en la legislatura anterior al autogolpe.

29. Un estudio comparativo entre los distintos países latinoamericanos acerca de las orientaciones hacia la democracia que tiene la ciudadanía, realizado por NDI/Römer y Asoc., indica que un $67 \%$ de los encuestados en Argentina y un $38 \%$ de los individuos encuestados en Perú (Chile, 74\%; El Salvador, 61\%; México, 50\%; Colombia, 37\%) está satisfecho con la democracia a pesar del desempeño de los actores involucrados y las instituciones políticas. Lipset y Schneider, en un trabajo sobre el papel de la dirigencia norteamericana señalaron que: “....aunque la mayoría de los norteamericanos tienen una alta estima por las instituciones democráticas..., ellos casi siempre han objetado la forma en que dichas instituciones operan y el desempeño de sus líderes..." (Catterberg, 1989).

30. La exposición de la hipótesis de los resultados de la democracia, analizada por ejemplo para el caso español por Maravall (1996), excede el marco del presente trabajo. A pesar de ello, consideramos importante señalar la necesidad de interpretar este tipo de procesos desde distintas líneas de análisis.

31. La pregunta administrada fue: "¿Qué grado de acuerdo mostraría Ud. con la afirmación de que la democracia es peligrosa porque puede traer desorden y desorganización”. Respuesta: muy de acuerdo más o menos de acuerdo - más o menos en desacuerdo - muy en desacuerdo - no sabe - no contesta. 


\section{Atributos positivos de la democracia}

El concepto de democracia ha caminado, históricamente, de la mano de dos pilares: uno de ellos, reivindica el principio libertario, se asienta en la tradición anglosajona y supone que la libertad está vinculada con la tolerancia y con el reconocimiento de las minorías políticas. La otra mirada focaliza en la idea de igualdad y se origina en la filosofía política francesa. La doctrina igualitaria resalta la noción de ciudadanía que regula de manera uniforme los derechos y las obligaciones de los individuos frente al poder político. La mayor expresión de esta idea se encuentra plasmada en el sufragio universal (Catterberg, 1989). Como régimen político, la democracia incluye estas dos dimensiones: la libertaria y la igualitaria ${ }^{32}$.

¿Qué esperan los parlamentarios de la democracia?. Libertades políticas, igualdad de oportunidades o de condiciones socio-económicas, respeto a los derechos humanos, mayor nivel de ingresos para la población o sólo la existencia de un procedimiento por medio del cual los ciudadanos puedan elegir a aquellos que ocuparán los cargos públicos. A partir de lo que se destaque como atributos positivos del régimen democrático, se podría identificar el reforzamiento de un aspecto del régimen político ${ }^{33}$ :

- una "democracia participativa": Se puede elegir a las autoridades de gobierno (elecciones periódicas); Se puede participar en las decisiones.

- una "democracia social": La economía crece más (bienestar); Se crean mejores oportunidades de desarrollo personal; Disminuye la pobreza; Se produce una mayor distribución de los ingresos;

- una "democracia liberal": Se asegura la libertad de las personas (pluralismo); Se produce una mayor convivencia; Se solucionan los problemas en forma pacífica; Se asegura el respeto a los derechos humanos (amparo de las minorías políticas).

Las variaciones en los fundamentos subjetivos de la democracia traducen una concepción específica de lo que se entiende por ese régimen político. Según el Cuadro n ${ }^{\circ} 4$, los diputados argentinos entrevistados señalaron que el principal atributo de la democracia es que : asegura la libertad de las personas (47\%); asegura el respeto a los derechos humanos $(16 \%)$ y permite la elección de las autoridades de gobierno (15\%).

Ninguno de los diputados argentinos entrevistados consideró la posibilidad de que bajo un régimen político democrático disminuyera la pobreza; se crearan mejores oportunidades de desarrollo personal o se produjera una mayor distribución de los ingresos. En este sentido, puede considerarse que los parlamentarios argentinos, en el momento de evaluar los atributos de la democracia, privilegian la dimensión liberal y, en menor medida, la dimensión participativa. Y, en ningún caso, la dimensión social de la democracia. Por su parte, los parlamentarios peruanos al ser consultados coincidieron con los argentinos al señalar el principal atributo de la democracia, dado que un $36 \%$ de
CUADRO N ${ }^{\circ} 4$

\begin{tabular}{l|c|c}
\hline \multicolumn{3}{c}{ Principal atributo de la democracia $(\%)^{34}$} \\
\hline & Argentina & Perú \\
\hline La economía crece más & 2 & 9 \\
\hline $\begin{array}{l}\text { Se crean mejores oportunidades } \\
\text { de desarrollo personal }\end{array}$ & 0 & 14 \\
\hline Se produce una mayor convivencia & 7 & 7 \\
\hline Disminuye la pobreza & 0 & 6 \\
\hline Asegura la libertad de las personas & 47 & 36 \\
\hline $\begin{array}{l}\text { Se asegura el respeto a los } \\
\text { derechos humanos }\end{array}$ & 16 & 8 \\
\hline $\begin{array}{l}\text { Se solucionan los problemas } \\
\text { en forma pacífica }\end{array}$ & 5 & 3 \\
\hline $\begin{array}{l}\text { Se puede elegir a las autoridades } \\
\text { de gobierno }\end{array}$ & 15 & 8 \\
\hline $\begin{array}{l}\text { Se produce una mayor distribución } \\
\text { de los ingresos }\end{array}$ & 0 & 1 \\
\hline Se puede participar en las decisiones & 7 & 8 \\
\hline Otras & 1 & 0 \\
\hline Total & 100 & 100 \\
\hline $\mathrm{n}$ & 68 & 87 \\
\hline
\end{tabular}

Fuente: Investigación Élites Parlamentarias en América Latina

los diputados indicaron la capacidad de este régimen de asegurar la libertad de las personas. Pero los diputados peruanos prefirieron, también, los aspectos sociales de la democracia, indicando en un $14 \%$ que se crean mejores oportunidades de desarrollo personal y en un $9 \%$ que en un contexto democrático la economía crece más.

A partir de los resultados presentados podríamos interpretar que la dimensión liberal de la democracia tiene un fuerte arraigo en los valores de las élites parlamentarias argentina y peruana. Si los diputados creen que la democracia es sólo lo estrictamente liberal y participativo (en sentido procedimental, elección de los candidatos para ocupar cargos públicos), difícilmente pueda extenderse la democracia a otros ámbitos. No se puede pretender extraer algo

32. Excede el objeto de este trabajo la discusión filosófica acerca de los significados de la democracia; si se quiere profunizar en este sentido ver Held (1992).

33. El agrupamiento en estas tres dimensiones de las categorías de análisis utilizadas en el cuestionario administrado a los legisladores es sólo para fines explicativos. La construcción de éstas dimensiones se realizó a partir de una primera formulación desarrollada por Edgardo Catterberg (1989).

34. La pregunta realizada fue la siguiente: "De esta lista, ¿cuáles son en su opinión las tres principales ventajas de la democracia por orden de preferencia". Repuesta: La economía crece más; Se crean mejores oportunidades de desarrollo personal; se produce mayor convivencia; Disminuye la pobreza; Asegura la libertad de las personas; Se asegura el respeto a los derechos humanos; Se solucionan los problemas en forma pacífica; Se puede elegir a las autoridades de gobierno; Se produce una mejor distribución de los ingresos; Se puede participar en las decisiones; Otra; No sabe; No contesta. 
de una cosa, que se sabe que no va a ser brindado por ella. En este sentido, Diamond (1993) sostiene que “... la erosión de la democracia... puede consistir en un sutil (y no tan sutil) deterioro cultural, en el que los compromisos de los políticos con la democracia adquieren un carácter instrumental y los demócratas pierden la fuerza dinamizadora de la convicción profunda en el valor intrínseco de la democracia". Pero también es importante precisar que aquello que se pretende de la democracia puede ser justamente lo que menos se ha tenido. En este sentido, se debe recordar las experiencias históricas de cada uno de estos países, donde la violación a los derechos humanos y a la libertad de los ciudadanos ha sido una constante en el tiempo.

\section{Instituciones democráticas}

¿Qué es lo que permite a algunos países latinoamericanos ser considerados como poliarquías?. Que las elecciones estén institucionalizadas. La noción de elección de los gobernantes por los ciudadanos es el primer indicador a constatar cuando intentamos saber si un país tiene una "democracia política" (O`Donnell; 1995). Como mencionamos anteriormente, en la década del ochenta, muchos países de América Latina, celebraron el retorno de la competencia electoral. Argentina y Perú no fueron la excepción. La naturaleza cada vez más abierta de estos procesos generó nuevas oportunidades para la construcción de instituciones democráticas (Mainwaring y Scully; 1997).

Las elecciones son el mecanismo adecuado para expresar las preferencias políticas. En el Cuadro $\mathrm{n}^{\circ} 5$ vemos como, tanto los diputados argentinos $(97 \%)$ como los peruanos $(97 \%)$ consideraron que, en un contexto de pluralismo y amplia competencia partidista, los comicios electorales son siempre el mejor medio para que las personas manifesten sus preferencias políticas. Sólo un 3\% de legisladores de cada grupo se manifestó en desacuerdo con ésta cuestión. Estos resultados son más que obvios dado que aquellos que se benefician con la vigencia de este tipo de institución política son quienes respondieron el cuestionario administrado. De todos modos, esta homogeneidad de opinión resulta interesante, sobre todo a la luz de otras respuestas acerca de las instituciones democráticas.

\section{CUADRO N" 5}

Valoración de las elecciones como medio para expresar las preferencias $(\%)^{35}$

\begin{tabular}{l|c|c}
\hline & Argentina & Perú \\
\hline Acuerdo & 97 & 97 \\
\hline Desacuerdo & 3 & 3 \\
\hline Total & 100 & 100 \\
\hline $\mathrm{n}$ & 68 & 87 \\
\hline
\end{tabular}

Fuente: Investigación Élites Parlamentarias en América Latina

También se les consultó a los diputados de los dos países acerca de la confianza que le merecían los comicios celebrados en su país en la última década, dado que una condición necesaria para que la "democracia política" se consolide es que las elecciones sean "limpias, competitivas y regulares" (O'Donnell; 1995). Los diputados argentinos respondieron en un $80 \%$ que la manera en que se realizaron los comicios les merecía mucha confianza. Mientras ningún diputado desconfió de los procesos electorales; las pequeñas diferencias de valoración se presentaron cuando analizamos las respuestas agrupándolas por partido político: el $96 \%$ de los justicialistas expresaron su máxima confianza en esos procesos; mientras que los radicales $(68 \%)$ y los frepasistas (67\%) lo hicieron en menor medida. Si bien la diferencia es de grado (entre confianza y mucha confianza) cerca del $30 \%$ de los diputados de partidos opositores valoraron en menor medida a los comicios.

En el caso de Perú, el 15\% de los diputados entrevistados manifestaron su desconfianza en relación al modo que se realizaron las elecciones en la última década en su país. Los diputados del APRA (67\%) son los que menos confianza tienen en los procesos electorales, mientras que sólo el $17 \%$ de UPP opinaron de este modo. Por otra parte, ningún diputado de NM/C'90 desconfió de los procedimientos y de los resultados electorales.

\section{CUADRO N 6: ARGENTINA}

Confianza en las elecciones de la última década por partido político $(\%)^{36}$

\begin{tabular}{l|r|r|r|r|r}
\hline & \multicolumn{1}{|c|}{ PJ } & \multicolumn{1}{c|}{ UCR } & FREPASO & OTROS & TOTAL \\
\hline Poca confianza & 0 & 0 & 0 & 0 & 0 \\
\hline Confianza & 4 & 32 & 33 & 17 & 20 \\
\hline Mucha Confianza & 96 & 68 & 67 & 83 & 80 \\
\hline Total & 100 & 100 & 100 & 100 & 100 \\
\hline $\mathrm{n}$ & 23 & 19 & 12 & 12 & 66 \\
\hline
\end{tabular}

Fuente: Investigación Élites Parlamentarias en América Latina

Como muestran los Cuadros $\mathrm{n}^{\circ} 6 \mathrm{y} \mathrm{n}^{\circ} 7$, los diputados del oficialismo confían más que los de la oposición en el modo en que se llevan a cabo los procesos electorales y en la certeza de sus resultados. Quizás la explicación se encuentre en que dado que en estos países las elecciones son organiza-

35. La pregunta administrada fue: "En un contexto de pluralismo y amplia competencia partidista, ¿estaría usted de acuerdo con la afirmación de que las elecciones son siempre el mejor medio para expresar unas determinadas preferencias políticas?”. Respuesta: muy de acuerdo - más o menos de acuerdo - más o menos en desacuerdo - muy en desacuerdo - no sabe - no contesta. A los efectos de este análisis los rangos se han recodificado en acuerdo y desacuerdo.

36. La pregunta administrada fue la siguiente:¿Cuál es el grado de confianza que le han merecido los procesos electorales que han tenido lugar en su país en la última década?. Valore de 1 a 5 , siendo 1 un grado de confianza mínimo y 5 un grado de confianza máximo". Al momento de realizarse esta pregunta no se distinguió en un tipo específico de elección (presidencial, legislativa, provincial o muncipal) sino que se consultó acerca de los comicios en general celebrados en la última década en su país. 
CUADRO N 7: PERÚ

Confianza en las elecciones de la última década por partido político $(\%)^{36}$

\begin{tabular}{l|r|r|r|r|r}
\hline & NM/C'90 & UPP & APRA & OTROS & TOTAL \\
\hline Poca confianza & 0 & 17 & 67 & 44 & 15 \\
\hline Confianza & 4 & 58 & 33 & 25 & 18 \\
\hline Mucha Confianza & 96 & 25 & 0 & 31 & 67 \\
\hline Total & 100 & 100 & 100 & 100 & 100 \\
\hline $\mathrm{n}$ & 51 & 12 & 6 & 16 & 85 \\
\hline
\end{tabular}

Fuente: Investigación Élites Parlamentarias en América Latina

das por agencias controladas por el gobierno, los diputados oficialistas tienden a valorar de manera más positiva aquello que hace su partido. En Argentina, el organismo encargado de organizarlas depende directamente del Ministerio del Interior. Salvo algunas denuncias en lugares del interior del país en las elecciones presidenciales de 1995; en general, no ha habido sospechas acerca de la limpieza de las elecciones en este país. En tanto, en el caso de Perú, autores como Palmer (1995) han denunciado irregularidades en los procedimientos y resultados electorales. También están aquellos (McClintock; 1996) que sospechan de las actitudes del presidente Fujimori, quien poco tiempo después del autogolpe y a los efectos de conseguir la mayoría necesaria en el Parlamento, destituyó al responsable del Jurado Nacional de Elecciones (JNE) y lo reemplazó por un hombre de su confianza. Parece ser que éste no actuó de manera neutra y favoreció a NM/C'90 en los comicios para elegir representantes en la Asamblea Constituyente y en el referéndum sobre la nueva constitución (ver nota $\mathrm{n}^{\circ} 16$ ).

Una vez consultados los diputados acerca de la importancia de llevar a cabo elecciones y de la confianza hacia los comicios se les preguntó acerca de una cuestión básica para la vigencia de la democracia contemporánea: la existencia de partidos políticos en un sistema democrático. Esta variable se presenta como significativa para la institucionalización del sistema de partidos ${ }^{37} \mathrm{y}$, según Mainwaring y Scully, es una parte importante del proceso de consolidación democrática, ya que "...la existencia o no de un sistema de partidos institucionalizado marca una honda diferencia en el funcionamiento de la política democrática..." (1997).

En el Cuadro $\mathrm{N}^{\circ} 8$, notamos que sólo el $4 \%$ de los diputados argentinos entrevistados consideraron la posibilidad de que la democracia pueda funcionar sin partidos políticos; mientras que el $96 \%$ restante descartó esta idea. En tanto, cerca del $31 \%$ de los diputados peruanos entrevistados se manifestaron de acuerdo con la idea de que la vida en democracia es posible sin partidos políticos ${ }^{38} \mathrm{y}$ cerca del $25 \%$ de los diputados dudaron acerca de la importancia de esta institución en un sistema democrático.

Es así como se puede identificar en las opiniones de los diputados peruanos cierta disonancia entre la percepción hacia las elecciones como medio para expresar las preferencias y la percepción hacia el papel de los partidos políticos

\section{CUADRO N ${ }^{\circ} 8$}

\begin{tabular}{l|c|c}
\hline \multicolumn{3}{c}{$\begin{array}{c}\text { ¿Qué grado de acuerdo mostraría usted con la afirmación de } \\
\text { que sin partidos políticos no puede haber democracia? (\%) }\end{array}$} \\
\hline & Argentina & Perú \\
\hline Muy de acuerdo & 96 & 44 \\
\hline Más o menos de acuerdo & 4 & 25 \\
\hline Más o menos en desacuerdo & 0 & 22 \\
\hline Muy en desacuerdo & 0 & 9 \\
\hline Total & 100 & 100 \\
\hline n & 67 & 85 \\
\hline
\end{tabular}

Fuente: Investigación Élites Parlamentarias en América Latina

en democracia. Pero a pesar de la relación directa entre la vigencia de las elecciones y la necesidad de partidos políticos en la vida democrática de los países desarrollados, nos preguntamos si necesariamente esto es así en otras regiones (como América Latina). Es decir, si siempre es necesaria la vigencia de partidos políticos en sistemas democráticos. Pensamos esto en dos sentidos. En primer lugar, porque el papel de los partidos políticos en América Latina ha sido, en general, secundario (Pásara; 1993b) y, en segundo lugar, porque quizás los partidos políticos han sido reemplazados por otras formas organizativas (agrupaciones de intereses, por ejemplo) que canalizan las demandas de la población.

\section{CUADRO N 9: ARGENTINA}

Valoración de los partidos políticos en un sistema democrático por partido político $(\%)$

\begin{tabular}{l|c|c|c|c}
\hline & PJ & UCR & FREPASO & OTROS \\
\hline Muy de acuerdo & 96 & 100 & 92 & 92 \\
\hline $\begin{array}{l}\text { Más o menos } \\
\text { de acuerdo }\end{array}$ & 4 & 0 & 8 & 8 \\
\hline $\begin{array}{l}\text { Más o menos } \\
\text { en desacuerdo }\end{array}$ & 0 & 0 & 0 & 0 \\
\hline Muy en desacuerdo & 0 & 0 & 0 & 0 \\
\hline Total & 100 & 100 & 100 & 100 \\
\hline $\mathrm{n}$ & 23 & 19 & 12 & 13 \\
\hline
\end{tabular}

Fuente: Investigación Élites Parlamentarias en América Latina

37. "Un sistema de partidos institucionalizado implica estabilidad en la competencia entre partidos, la existencia de partidos que tienen raíces más o menos estables en la sociedad, la aceptación de los partidos y de las elecciones como instituciones legítimas que deciden quién gobierna y la existencia de organizaciones de partidos que funcionan sobre la base de reglas y estructuras razonablemente estables" (Mainwaring y Scully, 1997).

38. $\mathrm{Al}$ intentar encontrar explicación acerca de estas orientaciones, realizamos una correlación entre esta variable y aquella que reflejaba la valoración de la democracia como fuente de desorden y desorganización y notamos que la relación existente entre ambas es significativa. 
En este sentido consideramos que quizás aquella afirmación sostenida por De Riz (1989) acerca de que “...en cada país latinoamericano la palabra 'partido' adopta una significación propia...” (Pásara; 1993b) puede llegar a ser cierta y, que dada la connotación que cada grupo le de a ese término y el papel histórico que estos hayan desempeñado dentro del sistema político, es posible que otras formas de organización los reemplacen y adopten sus funciones.

Mientras los diputados argentinos de la muestra consideraron que la democracia necesita de partidos políticos para funcionar y no presentaron casi diferencias en sus respuestas por pertenecer a uno u otro partido político; en el caso de Perú, las respuestas no fueron tan homogéneas. Los diputados que más estuvieron de acuerdo con la idea de que una democracia puede funcionar sin partidos políticos pertenecían a NM/C'90 (46\%), la agrupación que llevó al poder a Fujimori y que justamente no tiene estructura de partido ${ }^{39}$. A estos 23 diputados de NM/C'90 que piensan que es posible la democracia sin partidos hay que sumarles aquellos 12 que dudaron acerca de esta cuestión. Entonces, solo 15 de los diputados oficialistas entrevistados defendieron la existencia de partidos políticos en democracia. También hubo diputados de otros partidos políticos (UPP, 8\%; APRA, 14\%; OTROS, $12 \%$ ) que opinaron que una democracia no necesita de ellos para funcionar.

\section{CUADRO N 10 : PERÚ}

Valoración de los partidos políticos en un sistema democrático por partido político $(\%)$

\begin{tabular}{l|c|c|c|c}
\hline & NM/C'90 & UPP & APRA & OTROS \\
\hline Muy de acuerdo & 30 & 59 & 72 & 63 \\
\hline $\begin{array}{l}\text { Más o menos } \\
\text { de acuerdo }\end{array}$ & 24 & 33 & 14 & 25 \\
\hline $\begin{array}{l}\text { Más o menos } \\
\text { en desacuerdo }\end{array}$ & 36 & 0 & 0 & 6 \\
\hline $\begin{array}{l}\text { Muy en desacuerdo } \\
\text { Total }\end{array}$ & 10 & 8 & 14 & 6 \\
\hline $\mathrm{n}$ & 52 & 100 & 100 & 100 \\
\hline
\end{tabular}

Fuente: Investigación Élites Parlamentarias en América Latina

Sabemos que no es suficiente para la estabilidad y persistencia de un régimen democrático sólo el desarrollo de valores y creencias democráticas. Un régimen democrático necesita de instituciones democráticas. Entonces, ¿cuáles podrían ser las razones (o los factores) que justifiquen estas opiniones negativas hacia los partidos?. Diversos autores han analizado las causas de la crisis de los partidos políticos en América Latina. Algunos atribuyen esa crisis a la parlamentarización de los partidos (Bernales Ballesteros; 1995); a la alta volatilidad del electorado, la escasa penetración y relación entre la sociedad civil y la sociedad política y a las identidades partidarias fuertemente erosionadas; a la personalización del poder y la rela- ción más directa entre el líder y sus seguidores ${ }^{40}$ (Perelli; 1995) que hace casi innecesaria la presencia de organizaciones mediadoras, asociado esto también al papel de los medios de comunicación.

De todos modos, notamos que aquella tesis que sostenía que la institucionalización del sistema de partidos afectaba la democratización del régimen (Mainwaring y Scully; 1997 ) podría ser verificada. No olvidemos que uno de los factores necesarios para que un sistema de partidos se institucionalice es la aceptación de los partidos y las elecciones como instituciones legítimas y la existencia de organizaciones que funcionen sobre la base de reglas y estructuras estables. Si reflexionamos un momento acerca de las respuestas sobre la valoración de los partidos políticos, no sólo como organizaciones "relevantes" dentro del sistema político, sino también como percepción de la fortaleza de éstos en el sistema de partidos notamos que, en Argentina, los partidos políticos gozan de mayor fortaleza que en el caso peruano. Esto relaciona directamente con aquella idea que sostiene que Argentina tiene un sistema de partidos institucionalizados y Perú un sistema de partidos poco institucionalizado o incipiente ${ }^{41}$. Habría que preguntarse, entonces, hasta donde la consolidación de la democracia depende sólo de la cultura política y no (además) de otros factores como ser la institucionalización del sistema de partidos.

\section{Estabilidad y consolidación de la democracia}

Pensadores clásicos como Rousseau, Montesquieu y Tocqueville sostuvieron que la estabilidad de la democracia no puede ser garantizada sin la presencia de valores y actitudes compatibles con los fundamentos de ése régimen. La estabilidad de todo régimen político está condicionada por la presencia de una cultura política coherente con sus fundamentos. La relación causal entre el desarrollo de instituciones políticas democráticas y las pautas culturales preexistentes fue supuesta por Alexis de Toqueville al describir la democracia norteamericana. En "La democracia en América" (1835) sostiene que para conocer las leyes, las ideas y las costumbres que rigen la conducta de una nación

39. Otra cuestión importante a ser subrayada al analizar las opiniones acerca del papel de los partidos políticos en la vida democrática peruana tiene que ver con que muchas de las fuerzas políticas, que se encuentran representadas en el Congreso Nacional, no son partidos políticos tradicionales sino nuevas agrupaciones políticas. A los efectos de un análisis más profundo de este tema consideramos importante profundizar en el estudio del sistema de partidos. En este sentido,ver el trabajo de Mainwaring y Scully (1997), la compilación de los trabajos sobre Perú hecha por Tuesta Soldevilla (1996) y el trabajo de Reynoso (1997) para una comparación entre el sistema de partidos peruano y argentino.

40. Esta relación la expuso el propio Fujimori cuando sostuvo que: "En el Perú no existen partidos políticos (...) El poder soy yo, es verdad. Pero el poder que me fue dado por el pueblo.Yo lo represento”. Diario El Comercio, 21/6/93 (CFR: Sanborn/Panfichi;1996).

41. Según Cotler (1994), el régimen político peruano es un "régimen plebiscitario" en el cual las instituciones políticas han caído en un profundo descrédito, dificultando el camino hacia la consolidación democrática. Un estudio comparado acerca de los sistemas de partidos en estos dos países donde se sostienen argumentos similares es el de Reynoso (1997). 
hay que interiorizarse acerca del estado social de su pueblo. Para que una nación viva bajo reglas democráticas: las costumbres, las ideas, las prácticas societales de sus gentes (tanto de las élites como de la ciudadanía) deben ser democráticas. En este sentido, se entiende que ningún régimen político puede consolidarse o rutinizarse si, en primera instancia, no logra que sus reglas de juego e instituciones políticas sean estables (Catterberg; 1989).

\section{CUADRO No 11}

Opinión acerca de la estabilidad de la democracia $(\%)^{42}$

\begin{tabular}{l|c|c}
\hline & Argentina & Perú \\
\hline Muy estable & 44 & 20 \\
\hline Bastante estable & 50 & 45 \\
\hline Poco estable & 6 & 29 \\
\hline Muy inestable & 0 & 6 \\
\hline Total & 100 & 100 \\
\hline $\mathrm{n}$ & 68 & 86 \\
\hline
\end{tabular}

Fuente: Investigación Élites Parlamentarias en América Latina

Si recodificamos los resultados de esta pregunta en estable e inestable, notamos que sólo el 6\% de los legisladores argentinos consideran a la democracia como inestable mientras el $94 \%$ restante afirma que es estable. En tanto, el $35 \%$ de los diputados peruanos califican a la democracia como inestable y tan sólo el $65 \%$ de los diputados restantes la considera estable. Este tipo de percepción podría tener dos (o más) efectos posibles. Por una parte, que al percibirla como inestable, los diputados se comprometieran aún más con los principios, procedimientos e instituciones democráticas, con el fin de defenderla y (llegado el caso) protegerla ${ }^{43}$. El otro efecto posible es el de apatía y desinterés hacia el régimen político, por creer que su acción individual no es eficaz frente al sistema (García Beaudoux,Freidenberg y D`Adamo; 1997).

Pero, ¿a qué partido político pertenecen aquellos que consideran a la democracia peruana como inestable?. Los resultados muestran que aquellos que más perciben como inestable a la democracia peruana pertenecen a los partidos de la oposición (UPP: 83\%; APRA: 100\%; OTROS: 56\%). Solo un $8 \%$ de los diputados oficialistas reconocen que la democracia en su país es poco estable y los demás diputados de NM/C'90 la califican como muy estable y bastante estable $(92 \%)$.

¿Cuáles podrían ser la razones que llevan a los legisladores peruanos opositores al gobierno a percibir la inestabilidad del régimen democrático?. Parece claro que no existe una sola causa que explique estas opiniones sino que el origen de las mismas se encuentra en una multiplicidad de factores. En un sentido debemos destacar la experiencia negativa que Perú ha tenido en relación a la democracia y la serie de ciclos democráticos-autoritarios que imposibili-
CUADRO N 12: PERÚ

Estabilidad de la democracia perana según partido político $(\%)$

\begin{tabular}{l|c|c|c|c}
\hline & NM/C'90 & UPP & APRA & OTROS \\
\hline Muy estable & 33 & 0 & 0 & 0 \\
\hline Bastante estable & 59 & 17 & 0 & 44 \\
\hline Poco estable & 8 & 66 & 86 & 44 \\
\hline Muy inestable & 0 & 17 & 14 & 12 \\
\hline Total & 100 & 100 & 100 & 100 \\
\hline $\mathrm{n}$ & 51 & 12 & 7 & 16 \\
\hline
\end{tabular}

Fuente: Investigación Élites Parlamentarias en América Latina

taron la institucionalización de un régimen democrático. Entre 1940 y 1992, la duración promedio de los gobiernos —autoritarios-democráticos- ha sido de 3 años y 7 meses. Pero este dato por sí solo no nos explica la percepción de inestabilidad democrática de la élite peruana. No lo hace porque en Argentina también ha habido ciclos de inestabilidad política y sucesión de ciclos democráticos-autoritarios y los legisladores no perciben a la democracia argentina como inestable.

Se debe tener en cuenta otra serie de factores para la interpretación de estos datos: además de la contínua inestabilidad política del país; el escaso "aprendizaje político" y la relativa memoria democrática de sus élites políticas; la crisis de los partidos políticos, la presencia de "enclaves autoritarios”; la persistencia de liderazgos personalistas, la violación de las reglas de juego democráticas y los comportamientos autoritarios como el autogolpe que hizo Fujimori en 1992. La combinación de todos estos factores condicionan aún la estabilidad de la "democracia política" peruana (y como este es un primer paso hacia la consolidación de este régimen, mayores dificultades presentará entonces para su rutinización. Y por ello nos preguntamos, ¿Cómo ha de consolidarse o rutinizarse aquello que aún no es percibido como estable?).

Más allá de estas apreciaciones y considerando particularmente las percepciones de la élite peruana en relación a la estabilidad del régimen democrático, quisimos conocer que factores percibían como importantes las élites parlamentarias para la consolidación democrática. Sabemos que en el caso de que la élite parlamentaria crea que el régimen político en su país es estable no significa directamente que ese régimen se haya consolidado ${ }^{44}$. Entonces, ¿cuáles serían los

42. A fin de conocer la opinión de los legisladores argentinos y peruanos acerca de la estabilidad democrática, se formuló la siguiente consulta: "Hablemos de la democracia en su país. En su opinión, la democracia es hoy en su país”. Respuestas: muy estable - bastante estable - poco estable - muy inestable - no sabe - no contesta.

43. En general, cuando se han realizado golpes de estado en la región el acto simbólico de éste consistía en cerrar el Congreso Nacional.

44. Pueden rastrearse distintas líneas de análisis en este sentido; por un lado está aquella que explica cómo la ineficacia del régimen para garantizar el crecimiento económico y ofrecer pautas de bienestar a la población dificulta el funcionamiento regular de los sistemas democráti- 
factores que podrían afectar la consolidación democrática?. En el Cuadro ${ }^{\circ} 13$ se muestra que tanto para los diputados argentinos $(47 \%)$ como para los peruanos $(48 \%)$, los factores institucionales son los que en mayor grado pueden afectar el funcionamiento del régimen, dado que la consolidación democrática depende del consenso partidario acerca de la vigencia de la Constitución y las instituciones básicas del sistema. Y esta no es una apreciación menor. Significa que un primer paso en la consolidación democrática es el respeto por todos los actores de las instituciones formales del régimen (y habría que pensar, justamente, si ese consenso no supone la estabilidad de las reglas de juego). Pero ese es sólo un primer momento hacia la consolidación. A este habría que agregarle otro, el de la adecuación entre esas reglas formales y el comportamiento de los distintos actores (O'Donnell; 1995).

\section{CUADRO N ${ }^{\circ} 13$}

\begin{tabular}{l|c|c}
\hline \multicolumn{3}{c}{$\begin{array}{c}\text { Principal cuestión para la consolidación } \\
\text { de la democracia (\%) }\end{array}$} \\
\hline $\begin{array}{l}\text { Consenso entre los principales partidos } \\
\text { en la Constitución y las instituciones } \\
\text { básicas }\end{array}$ & Argentina & Perú \\
\hline $\begin{array}{l}\text { Los acuerdos económicos entre } \\
\text { gobiernos, sindicatos y empresarios }\end{array}$ & 47 & 8 \\
\hline $\begin{array}{l}\text { La descentralización y } \\
\text { democratización regional }\end{array}$ & 3 & 8 \\
\hline \begin{tabular}{l|c} 
La moderación de la izquierda \\
La plena confianza en los \\
procesos electorales
\end{tabular} & 6 & 21 \\
\hline $\begin{array}{l}\text { El control de la constitucionalidad de las } \\
\text { leyes por un Tribunal Constitucional } \\
\text { independiente y respetado }\end{array}$ & 12 & 0 \\
\hline $\begin{array}{l}\text { La investigación (y en algunos casos } \\
\text { el castigo) de los actos ilegales y } \\
\text { criminales de las autoridades }\end{array}$ & 23 & 6 \\
\hline $\begin{array}{l}\text { La tolerancia de la derecha } \\
\text { Otras }\end{array}$ & 7 & 2 \\
\hline $\begin{array}{l}\text { Total } \\
\text { n }\end{array}$ & 08 & 0 \\
\hline
\end{tabular}

Fuente: Investigación Élites Parlamentarias en América Latina

En Perú, Fujimori no respetó las reglas de juego vigentes, ni la Constitución de 1979 ni a la élite parlamentaria elegida democráticamente por los ciudadanos. Tampoco buscó consensos ${ }^{46}$, por el contrario, siempre imprimió una actitud de confrontación en sus discursos y en sus actos (antagónica al diálogo). Hasta “...resulta imposible considerar a Fujimori — durante su período constitucional- como un gobernante respetuoso de las Constitución y sus leyes..." (Planas; 1996). Algunos autores (Cotler; 1995) consideran que Fujimori al ser un "outsider" ${ }^{47}$ tiene una mayor tendencia a gobernar sin respetar las reglas formales.

Si al estilo político del presidente peruano se le agrega cierta debilidad del sistema de partidos, inestabilidad y volatilidad partidaria y una escasa penetración de los partidos en la sociedad se puede percibir un escenario proclive a permitir comportamientos fuera de las "reglas de juego" (Reynoso, 1997). En este marco, los caminos no conducen precisamente hacia los consensos partidarios y es natural que los legisladores perciban a estas cuestiones como significativas para la consolidación de la democracia.

Y en el caso de Argentina, ¿porqué los legisladores perciben a los factores institucionales como condicionantes de la consolidación democrática?. Diversos autores (Reynoso; 1997) se han preguntado acerca de la posibilidad de una "fujimorización" ${ }^{48}$ en Argentina. Es decir, que ante los conflictos ejecutivo-legislativo el presidente Menem procediera a actuar en el mismo sentido que Fujimori, cerrando el Congreso Nacional y desatendiendo las "reglas de juego" democráticas. Las posibilidades de que esto ocurra están cada vez más lejanas. Pero esto no significa que en Argentina no haya habido conflictos entre poderes ${ }^{49}$ y que el ejecutivo no haya traspasado los límites de sus funciones y se haya inmiscuido en materias puramente legislativas. Por el contrario, diversos estudios (Molinelli, 1996; Ferreira Rubio y Goretti, 1995) muestran las relaciones conflictivas entre estos dos poderes. Pero así como ocurrió en Brasil, (con Color de Mello), o en Venezuela, (con Carlos Andrés Peres), los conflictos institucionales pueden

cos (Maravall; 1996). En tanto que, otros estudios se centran en los facto res institucionales como las variables explicativas de la debilidad demo crática (O’Donnell; 1995).

45. La pregunta realizada fue la siguiente: “De entre estas ocho características, elija las tres que a usted le parezcan más relevantes para la consolidación democrática por orden de preferencia”. Respuesta: Consenso entre los principales partidos en la Constitución y las instituciones básicas; Los acuerdos económicos entre gobiernos, sindicatos y empresarios; La descentralización y democratización regional; La moderación de la izquierda; La plena confianza en los procesos electorales; E control de la constitucionalidad de las leyes por un Tribunal Constitucional Independiente y respetado; La investigación (y en algunos casos el castigo) de los actos ilegales y criminales de las autoridades; La tolerancia de la derecha; Otra; No sabe; No contesta.

46. Algunas de las medidas tomadas por Fujimori sin buscar consenso y antes de realizar el autogolpe fueron: el decreto supremo que otorgó amnistía a los procesados, por medio del cual el ejecutivo usurpó funciones del poder judicial (septiembre 1990); la creación de la AADA, institución con super-poderes, que prescindía del Parlamento y de los ministros del Ejecutivo para legislar; la promulgación de la Ley de Presupuesto extrayéndole varios artículos de la aprobada por el Parlamento (Planas;1996).

47. Según Cotler (1994), puede entenderse como “outsiders" a aquellos actores ajenos a la élite política y con valores antipolíticos, que se olvidan rápidamente los compromisos contraídos.

48. Reynoso (1997) entiende por "fujimorización” a "una forma particular en que se resuelve, de manera procedimentalmente no democrática, las tensiones entre ejecutivo y legislativo. Es decir, una ruptura del régimen democrático".

49. En declaraciones al diario Clarín (5-9-90), Eduardo Duhalde, por entonces Vicepresidente de la Nación, reclamó la concentración del poder en manos del Presidente, reconoció que el Congreso demoraba mucho en estudiar los proyectos reclamados por el Poder Ejecutivo y admitió que en épocas de crisis, si las "leyes no salen”, el “...Presidente va a tener que hacer decretos..." (CFR: De Luca y Malamud; 1994). 
resolverse sin necesidad de llegar a la fujimorización (Reynoso; 1997). Y este parecería ser el caso de Argentina.

Los diputados peruanos consideran como cuestión importante para la consolidación de la democracia el consenso en la Constitución y las instituciones básicas, pero también la descentralización y democratización regional ${ }^{50}$ $(21 \%)$ y la plena confianza en los procesos electorales ${ }^{51}$ $(13 \%)$. En el caso argentino, la variable institucional se ve reforzada por la preferencia de un $23 \%$ de los entrevistados por el control de la constitucionalidad de las leyes por un Tribunal Constitucional independiente y respetado. Este control de una agencia estatal a otra es parte de lo que O’Donnell (1992) llama "accountability horizontal", un elemento esencial de toda poliarquía institucionalizada (y que muchas veces está ausente en las democracias políticas de América Latina). Pero ese "accountability" políticos perciban se manifiestan como una arista importante en el análisis de la realidad política de un país. No existe la posibilidad de perdurabilidad y consolidación de un régimen democrático, sino existe voluntad y "deseabilidad" por parte de los actores políticos y sociales de mantener el régimen independientemente de los resultados que se alcancen (Garretón, 1991; Lamounier). Si se espera, por ejemplo, que en el marco de un régimen democrático se posibilite una mayor redistribución de ingresos; se garantice el crecimiento económico o se cancelen todos los compromisos de la deuda externa; las expectativas en relación al régimen van a ser de un modo determinado y los problemas que se perciban como amenaza para la consolidación de los procedimientos y las instituciones democráticas se verán condicionadas por esta visión. Ahora bien, si la concepción democrática está vinculada a una perspectiva institucional o se asocia a este régimen con la garantía de

CUADRO N ${ }^{\circ} 14$

\begin{tabular}{|c|c|c|c|c|c|c|}
\hline \multicolumn{7}{|c|}{ Amenazas al proceso de consolidación democrática (\%) $\%$} \\
\hline & \multicolumn{3}{|c|}{ Argentina } & \multicolumn{3}{|c|}{ Perú } \\
\hline & $\begin{array}{c}\text { Poco } \\
\text { Importante }\end{array}$ & Importante & $\begin{array}{c}\text { Muy } \\
\text { Importante }\end{array}$ & $\begin{array}{c}\text { Poco } \\
\text { Importante }\end{array}$ & Importante & $\begin{array}{c}\text { Muy } \\
\text { Importante }\end{array}$ \\
\hline Las relaciones entre las Fuerzas Armadas y el gobierno & 87 & 9 & 4 & 37 & 29 & 34 \\
\hline La crisis económica & 26 & 30 & 44 & 24 & 30 & 46 \\
\hline El terrorismo & 68 & 20 & 12 & 41 & 6 & 53 \\
\hline El desempleo & 13 & 20 & 67 & 19 & 37 & 44 \\
\hline El mal funcionamiento del Poder Judicial & 11 & 25 & 65 & 16 & 36 & 48 \\
\hline El narcotráfico & 35 & 38 & 27 & 13 & 31 & 56 \\
\hline La deuda externa & 35 & 32 & 32 & 45 & 34 & 21 \\
\hline La delincuencia, asaltos y robos & 63 & 24 & 12 & 47 & 37 & 16 \\
\hline Las huelgas, paros y conflictos laborales & 72 & 22 & 6 & 68 & 22 & 10 \\
\hline La extrema pobreza & 14 & 22 & 64 & 16 & 30 & 54 \\
\hline El desinterés de la gente por la política & 21 & 30 & 49 & 47 & 26 & 26 \\
\hline Los conflictos entre el poder legislativo y el ejecutivo & 45 & 33 & 22 & 47 & 26 & 26 \\
\hline
\end{tabular}

Fuente: Investigación Élites Parlamentarias en América Latina

va más allá del mero control de una agencia a otra ya que es una “...característica global del sistema legal aplicado al funcionamiento del estado, el régimen y el gobierno..." (O`Donnell; 1995). La falta de control entre las propias agencias estatales (accountability horizontal); desde la ciudadanía hacia los gobernantes en las elecciones (accountability vertical formal) y en cualquier otro momento que no sea demandado por el sistema (accountability vertical espontáneo) ${ }^{52}$ dificulta la consolidación de cualquier "democracia política".

\section{Amenazas al proceso de consolidación democrática}

El papel de los políticos, no como sujetos silenciosos y obedientes bajo las directrices de los partidos, sino como "actores estratégicos" es de singular relevancia a la hora de estudiar los procesos de democratización (Alcántara, 1995). Las amenazas al proceso de consolidación que esos
50. Para comprender mejor esta cuestión habría que profundizar en el estudio del sistema político y del sistema electoral peruano.

51. No resulta llamativo esta preocupación de los diputados peruanos por la confianza en los procesos electorales como cuestión importante en el proceso de consolidación democrática, dado que cerca del $15 \%$ de los diputados peruanos desconfiaron de los procedimientos y resultados de las elecciones celebradas en su país en la última década.

52. O'Donnell (1995) ha estudiado extensamente el papel del accountability en las "democracias políticas" de América Latina. Para una reformulación del concepto ver García Beaudoux, Freidenberg y D'Adamo (1997).

53. "Hay temas que algunas personas creen que representan una amenaza o un riesgo para la consolidación de la democracia en su país. De los siguientes temas: chasta que punto cree que resultan hoy una amenaza para la democracia en su país?. Valore de 1 a 5 , siendo uno muy bajo riesgo o amenaza y cinco mucho riesgo o amenaza. Respuesta: Las relaciones entre Fuerzas Armadas y gobierno; La crisis económica; El terrorismo; El desempleo; El mal funcionamiento del Poder Judicial; El narcotráfico; La deuda externa; La delincuencia, asaltos y robos; Las huelgas, paros y conflictos laborales; La extrema pobreza; El desinterés de la gente por la política; Los conflictos entre el poder legislativo y el ejecutivo. A partir de los rangos establecidos en la encuesta original, se han reagrupados de la siguiente manera: mínimo + poco= poco importante; mediano= importante; importante + muy importante $=$ muy importante 
libertad y el respeto a los derechos humanos; las amenazas que se perciban serán diferentes.

En el Cuadro ${ }^{\circ} 14$ vemos que las mayores amenazas a la democracia argentina percibidas por la élite parlamentaria son el desempleo (67\%); el mal funcionamiento del Poder Judicial $(65 \%)$ y la extrema pobreza (64\%). En tanto, el narcotráfico (56\%); la extrema pobreza (54\%) y el terrorismo $(53 \%)$ son las amenazas que los legisladores peruanos perciben para el régimen político de su país. Las amenazas que los dos grupos perciben están relacionadas de manera directa con los problemas que actualmente se le presentan al gobierno de su país y que afectan la gobernabilidad del sistema. Pero se presenta una diferencia significativa entre los dos países. En el caso argentino, las amenazas señaladas están sujetas a la decisión y capacidad del Gobierno por superarlas a diferencias de dos de las amenazas señaladas por los diputados peruanos (narcotráfico y terrorismo).

Según muestran los resultados, existen diferencias significativas entre lo que es considerado como amenaza para uno u otro país. En este sentido, consideramos importante profundizar, por ejemplo, en la percepción de los diputados hacia las Fuerzas Armadas, dado el papel que estas han protagonizado en la inestabilidad democrática de América Latina. Mientras un $34 \%$ de los entrevistados peruanos señala como una amenaza muy importante para la consolidación democrática el modo en que las Fuerzas Armadas se relacionan con el gobierno; sólo el $4 \%$ de los legisladores argentinos lo perciben de esta manera ${ }^{54}$. En función de esas respuestas, le preguntamos a los diputados acerca del papel que esta institución ha desempeñado en el período 19711991 en su país y acerca de la imagen que actualmente tienen de ella.

\section{CUADRO N 15}

Imagen de las Fuerzas Armadas (\%)

\begin{tabular}{l|c|c|c|c}
\hline & \multicolumn{2}{|c|}{$1971-199155$} & \multicolumn{2}{c}{ En la actualidad 56 } \\
\hline & Argentina & Perú & Argentina & Perú \\
\hline Negativa & 89 & 40 & 9 & 25 \\
\hline Normal & 9 & 53 & 40 & 13 \\
\hline Positiva & 2 & 7 & 51 & 62 \\
\hline Total & 100 & 100 & 100 & 100 \\
\hline $\mathrm{n}$ & 65 & 83 & 68 & 87 \\
\hline
\end{tabular}

Fuente: Investigación Élites Parlamentarias en América Latina

Si comparamos las opiniones de los legisladores argentinos hacia las Fuerzas Armadas en los dos momentos, notamos que la imagen ha mejorado notablemente (del 2\% al 51\% de imagen positiva de un período a otro). En aquel momento, las FF.AA. argentinas (apoyadas por grupos civiles) violaron el orden constitucional vigente y ocuparon ilegítimamente el poder. El "Proceso de Reorganización Nacional”, influenciado por los fundamentos de la Doctrina de Seguridad Nacional, actuó como “...un poder de facto que ejerció atribuciones de todos y cada uno de los poderes...”, es decir, como un poder de hecho "...sólo limitado por los hechos y por el poder de quien lo ejerce...” (Groisman; 1984). Consistió en la sistemática violación a los derechos humanos que produjo la desaparición de cerca de 30.000 personas (Informe Nunca Más) y en la implementación de políticas que provocaron una profunda crisis socio-económica, generando resentimiento en los sectores populares y de importantes grupos de la burguesía (que tradicionalmente eran el sustento social de las FF.AA). Desde aquellos años a la actualidad, las FF.AA. han sido progresivamente "encapsuladas" (Strada Saenz; 1994), subordinadas al orden constitucional y sin capacidad para ejercer ningún papel político ${ }^{57}$. En el caso de los diputados peruanos, la imagen de las FF.AA también mejoró notablemente de un momento a otro (de $7 \%$ a $62 \%$ ), pero la situación de estas en el Perú, en estos momentos, es distinta. Las Fuerzas Armadas peruanas aún tienen capacidad de veto en el proceso de toma de decisiones de su país y esto perjudica el proceso de consolidación democrática ya que, de este modo, persiste un fuerte "enclave autoritario" (Garretón; 1991).

Otra de las cuestiones que resulta llamativa es que en Argentina, los legisladores, no hayan percibido a los conflictos entre el poder legislativo y el poder ejecutivo como grandes amenazas al proceso de consolidación del régimen. Esto es comprensible en las respuestas de los diputados peruanos ya que, luego del cierre del Congreso y la elección de nuevos legisladores, el oficialismo tiene mayoría en la Cámara y han disminuido los conflictos entre ambos poderes (en comparación al período anterior al autogolpe). Además, la composición de la muestra utilizada para este trabajo se encuentra sobrerepresentada de legisladores de NM/C 90 . Pero en el caso de Argentina es distinto. El presidente Menem ha apelado en muchas ocasiones a los "decretos de necesidad y urgencia”, ejerciendo facultades legislativas y limitando las funciones del Congreso Nacional (Ferreira Rubio y Goretti; 1993).

54. La explicación de este fenómeno en Argentina podría encontrarse en que el gobierno de Carlos Menem desarticuló a las Fuerzas Armadas (tanto a nivel político como presupuestariamente). Por primera vez, desde 1930, la cuestión militar está fuera de la agenda política. Según Huntington (1991), la desarticulación de las Fuerzas Armadas no es algo aleatorio, dado que forma parte de una tendencia global que comparten todas las nuevas democracias.

55. La pregunta fue: “¿Cómo evalúa usted el papel de las Fuerzas Armadas en su país entre 1970 y 1991?. Califique su actuación según una escala que vaya de 1 , muy negativo, a 5 , muy positivo".

56. El interrogante fue el siguiente: "Siguiendo la misma escala: ¿Cómo evalúa el papel de las Fuerzas Armadas en la actualidad?”.

57. A partir de la sanción de las Leyes de Defensa Nacional y de Seguridad Interior y de las políticas de ajuste presupuestario, implementadas por el gobierno de Menem, las FF.AA. han experimentado una redefinición de sus funciones en el marco del orden constitucional vigente. En estos momentos, una de las tareas más importantes de los militares argentinos es participar en misiones de paz de caracter internacional (bajo el concierto de la Organización de Naciones Unidas). 


\section{ALGUNAS NOTAS A MODO DE CONCLUSIÓN}

La presencia de valores y actitudes democráticas no es una precondición necesaria para que surja un régimen político democrático, pero su existencia puede llegar a ser importante para que el régimen se consolide (Catterberg; 1989). Un paso en este sentido es que las élites políticas detenten estas creencias y que, eventualmente, promuevan la expansión de estas ideas a otras élites cercanas e, incluso, a la ciudadanía (Diamond, 1993).

A la luz de los resultados presentados, podríamos suponer que las actitudes de la élite parlamentaria argentina son más democráticas que las actitudes de la élite parlamentaria peruana.

Las opiniones de los dos grupos de legisladores coincidieron sólo en tres de las variables analizadas: en los atributos de la democracia; en la valoración de las elecciones como el mejor medio para expresar las preferencias políticas y en los factores importantes en la consolidación democrática. Por una parte, los diputados argentinos $(47 \%)$ y peruanos $(36 \%)$ consideraron que el mayor atributo de la democracia era de naturaleza liberal; es decir, el hecho de que este régimen asegurara la libertad de las personas. Por otra parte, los dos grupos (97\%) también coincidieron en aceptación de las elecciones como mejor medio de participación política. En tanto, los argentinos $(47 \%)$ y los peruanos $(48 \%)$ señalaron al consenso entre los principales partidos en la Constitución y las instituciones básicas como factor principal en el proceso de consolidación democrática.

Ahora bien, en las demás variables, los dos grupos se han posicionado de manera distinta. Las diferencias se presentan en la valoración de la democracia como mejor sistema político; como fuente de desorden y desorganización; en la percepción del papel de los partidos políticos en un régimen democrático; en el nivel de confianza en los procesos electorales y sus resultados; en la estabilidad de la democracia y en las amenazas que cada grupo percibe para la consolidación de la democracia en su país.

Sabemos que para que una democracia sobreviva las élites políticas tienen que creer en ella y deben tener habilidad política para crearla, mantenerla (Huntington, 1991) o llegado el caso reinventarla (Diamond, 1993). Es muy importante que las élites parlamentarias crean en la democracia. En el caso argentino, no habría dificultades. La élite parlamentaria (97\%) es proclive a articular comportamientos leales hacia la democracia (por lo menos, en el nivel de las actitudes) y, como sabemos, esto favorece la consolidación del régimen político. Pero en en el caso de Perú no ocurre lo mismo. Los legisladores peruanos (21\%), y más precisamente, los de NM/C'90 (30\%), no creen de manera profunda en la democracia; dudan acerca de las bondades de este sistema y es poco probable que, en el momento de que la democracia tenga problemas; ellos la defiendan. Y es que no se puede defender aquello en lo que no se cree. También los legisladores peruanos (a diferencia de los argentinos $-3 \%$-) desconfiaron de la capacidad de la democracia para asegurar el orden.
Muchos de ellos (34\%) creen que la democracia es peligrosa porque puede generar desorden y desorganización. $\mathrm{Si}$ bien es cierto que ambas élites parlamentarias consideran que las elecciones son el mecanismo más adecuado de participación política; los diputados peruanos $(15 \%)$ desconfían de los resultados de esas elecciones que apoyan (mientras que ningún diputado argentino desconfió del proceso electoral).

Sabemos también de la importancia que han tenido los partidos políticos en los regímenes democráticos de los países desarrollados; sin embargo, en América Latina han desempeñado un papel secundario (Pásara; 1993b). Weffort (1992) entre otros considera que los partidos son muy importantes no solo para la estabilidad democrática sino también para el proceso de consolidación democrática, dado que son quienes deben aportar una “...clase política (élite política) imbuída de una conciencia general de su rol en (este) proceso..." y, sin élites políticas con conciencia democrática, no es posible consolidar un régimen democrático (Pásara; 1993b).

En este punto, los diputados argentinos y peruanos manifestaron una profunda diferencia. Mientras que muy pocos diputados argentinos $(4 \%)$ consideraron que la democracia no necesita de partidos políticos para funcionar; un número importante de diputados peruanos $(56 \%)$ dudaron acerca de esta idea. Y esta valoración es muy importante. Es que cuando las propiedades de la cultura política democrática se erosionan o no se renuevan a lo largo de las generaciones; las instituciones democráticas están en peligro. Además, como mencionamos anteriormente, la actitud que tanto la élite como los diversos grupos tengan hacia los partidos políticos como instituciones legítimas dentro del sistema político es uno de los indicadores a considerar cuando se intenta determinar el nivel de institucionalización de un sistema de partidos (Mainwaring y Scully; 1997). En este sentido, entonces, el sistema de partidos argentino estaría más institucionalizado que el peruano, el que tendría un sistema de partidos poco institucionalizado o incipiente. A mayor descrédito de las instituciones políticas del sistema político mayores son las dificultades que presenta el régimen para consolidarse. Como también sostienen Mainwaring y Scully (1997), el nivel de institucionalización afecta el proceso de democratización

Un régimen político para poder consolidarse o rutinizarse tiene que, en primer lugar, lograr que sus instituciones y reglas formales sean estables y, además, que los distintos actores lo perciban como tal. Mientras solo unos pocos diputados argentinos $(6 \%)$ perciben al régimen democráctico como poco estable; un grupo mayor de diputados peruanos $(35 \%)$ percibió a la democracia como inestable (poco estable + muy inestable). Los diputados de la oposición son los que más perciben la inestabilidad de este régimen político (UPP: 83\%; APRA: 100\%; OTROS: 56\% comparando con NM/C'90: 8\%).

Que la élite política posea valores democráticos como sustento de sus actitudes es importante para la estabilidad y rutinización de las reglas democráticas pero esto, por sí 
solo, no explica el desarrollo de un régimen político. La democracia política o electoral requiere para consolidarse la superación, por parte de las élites y de la ciudadanía, de cualquier tipo de percepción de amenaza. Esto es una condición necesaria para que la rutinización de las prácticas democráticas persistan en el tiempo. En los casos estudiados, las amenazas que se perciben son diferentes. En tanto, el desempleo (67\%), el mal funcionamiento del poder judicial $(65 \%)$ y la extrema pobreza $(64 \%)$ son las amenazas que los legisladores argentinos perciben para la democracia de su país; el narcotráfico (56\%), la extrema pobreza $(54 \%)$ y el terrorismo $(53 \%)$ son las amenazas que perciben los diputados peruanos.

Como mencionamos anteriormente, a pesar de que algunos de los países de la región cumplen formalmente con los atributos indicados como necesarios para que se alcance un régimen poliárquico; se presentan serias dificultades en el momento en que esos atributos se traducen en prácticas y comportamientos democráticos cotidianos. Decíamos también que las diferencias más significativas en este nivel se manifiestan en la concepción y en el significado de la democracia y, también, en el nivel e intensidad de implantación de la misma (Alcántara, 1997). Los datos que analizamos nos permiten corroborar una parte de esa premisa, dado que se presentan diferencias significativas en la percepción de la democracia (por ambos grupos). Los datos reflejan que las actitudes de la élite parlamentaria argentina son más democráticas que las actitudes de la élite parlamentaria peruana.

De este modo, Perú se enfrenta de manera más profunda a ese nuevo desafío que experimentan muchos países latinoamericanos, lo que O'Donnell (1995) ha denominado como una "segunda transición que va desde un gobierno democráticamente electo a un régimen democrático consolidado". En este marco, a las élites políticas se les presenta un nuevo (y no tan nuevo) desafío; el de comportarse democráticamente. Si se pretende que la democracia subsista en el tiempo; las élites deben profundizar la democratización del régimen. Comportarse democráticamente significa no solo el respeto formal a las reglas constitucionales y a las instituciones del sistema sino también el ejercicio de prácticas y comportamientos respetuosos de esas reglas. Quizás las élites políticas de algunos países latinoamericanos aún necesiten comprender que los problemas de la democracia se curan con más democracia.

\section{BIBLIOGRAFÍA}

Alcántara SÁEZ, M. (1995): "Gobernabilidad y Elite Política en América Latina". Seminario "Transformaciones de los sistemas políticos en América Latina”, Villa de Leyva, Colombia.

- (1997): "Democracia y valores democráticos en los diputados latinoamericanos". III Congreso de la Asociación Española de Ciencia Política y de la Administración. Salamanca, 2 al 4 de octubre de 1997.
AlCántara Sáez, M. y Llamazares V., I. (1997): “El análisis de los diputados latinoamericanos en el contexto de los estudios sobre la clase política. Características. Objetivos y estrategias de investigación". América Latina Hoy, $\mathrm{n}^{\circ} 16$.

Aguero Piwonka, F. y Torcal Loriente, M.: "Elites, factores estructurales y democratización. Una discusión de aportes recientes en la literatura". Revista de Estudios Políticos. $\mathrm{N}^{\mathrm{o}} 82$.

Almond, G. (1950): The American People and Foreing Policy. Nueva York: Harcourt.

Almond, G. y Verba, S. (1963): The Civic Culture. Princenton: Princenton University Press.

Bernales Ballesteros; E. (1995): "La crisis de los Partidos Políticos". En: Fernández Fontenoy, C.: Sociedad, Partidos y Estado en el Perí". Lima: Universidad de Lima.

Bobbio, N. (1983): "élite, teoría de". En: Bobbio, N., Pasquino, G. y Matteucci, N.: Diccionario de Política. México: Siglo XXI. 1995.

Botana, N.: Reportaje junto a Tulio Halperín Donghi. Clarín,12/10/97.

Bottinelli, O. (1995): "El Parlamento y su función política”. Cuadernos del CLAEH. N ${ }^{\circ}$ 73-74. $2^{\circ}$ serie, año 20. pp. 167-177.

CATterberg, E. (1989): Los Argentinos frente a la política. Buenos Aires: Planeta.

Cotler, J. (1994): Política y Sociedad en el Perú. Cambios y Continuidades. Lima: IEP.

DAHL, R. (1971): La poliarquía. Barcelona:Tecnos. 1989.

D’Adamo, O. y García Beaudoux, V. (1995): “Actitudes hacia la democracia: del modelo clásico liberal a las nuevas democracias participativas". En: D'ADAMO, O., García Beaudoux, V. y Montero, M. (comp.): Psicología de la acción política. Buenos Aires: Paidós.

De Luca, M. y Malamud, A. (1994): "Gobernabilidad e Instituciones: Argentina 1983-1993” En: PINTO, J. (Comp.): América Latina en la década de los 80. Repensando la transición a la democracia. Buenos Aires: UBA.

Diamond, L. (1993): Political Culture and Democracy in Developing Countries. Boulder: Lynne Rienner Publishers.

Fernández Fontenoy, C. (1995): Sociedad, Partidos y Estado en el Perú. Lima: Universidad de Lima.

Ferreira Rubio, D. y Goretti, M. (1993): "La emergencia y la relación entre el Ejecutivo y el Congreso durante la administración del presidente Menem: uso y abuso de los decretos de necesidad y urgencia". París: IPSA.

García Beaudoux, V. Freidenberg, F. y D'Adamo, O. (1997): “Acción Política y democracia: El problema de la eficacia externa”. En: GuzMÁn G., L.: Exploraciones de Psicología Política. Santiago: Universidad Diego Portales. 
García Delgado, D. (1995): Estado E Sociedad. Buenos Aires: Flacso-Tesis Norma.

Garretón, M. A.(1991): Cultura Política y sociedad en la Construcción Democrática. Santiago: Flacso. Programa Chile.

Groismann, E. (1984): El "Proceso de Reorganización Nacional" y el sistema jurídico. En: OszlaK, O.: "Proceso", Crisis y transición democrática-1. Buenos Aires: Centro Editor de América Latina.

Hartlyn, J. (1994): "Democracia en la actual América del Sur: Convergencias y diversidades”. Síntesis, n² 22, 17 51.

HeLD, D. (1992): Modelos de Democracia. Madrid: Alianza.

Higley, J. (1995): "Elites, Political". En: Encyclopedia of Democracy. Vol. II. London: Routledge.

Higley, J. y GunTher, R. (edit.) (1992): Elites and democratic consolidation in Latin America and Southern Europe. New York: Cambridge University Press.

Huntington, S. (1991): La Tercera Ola. Buenos Aires: Paidós. 1994.

Kenney, C. (1997): “Anti-Políticos, Intrusos y Política Democrática”, e politiké, n 3, 28-42.

- (1996): “¿Por qué el autogolpe? Fujimori y el Congreso, 1990-1992". En: Tuesta Soldevilla, F. (edit.): Los enigmas del poder. Fujimori 1990-1996. Lima: Fundación Friedrich Ebert.

LinZ, J. (1989): La quiebra de las democracias. Madrid: Alianza.

LinZ, J. y STEPAN, A. (1997): "Toward Consolidated Democracies”. En: Diamond, L., Plattner, M., YunHan Chu y Hung-Mao Tien (Edit.): Consolidating the Third Wave Democracies. Baltimore y London: The Jonhs Hopkins University Press.

Mainwaring, S. y Scully, T. (1997): "La institucionalización de los sistemas de partidos en la América Latina”. América Latina, Hoy, No 16.

Martínez, A. (1997): "Cultura Política, Gobernabilidad y Elites parlamentarias en América latina”, En: DEL Castillo, P. y CRespo, I.: Cultura Política. Valencia: Tenant lo blanch.

McClinTOCK, C. (1996): "La voluntad política presidencial y la ruptura constitucional de 1992 en el Perú”. En: Tuesta Soldevilla, F. (edit.): Los enigmas del poder. Fujimori 1990-1996. Lima: Fundación Friedrich Ebert.

Molinelli, G. (1996): "Las relaciones PresidenteCongreso en Argentina '83-995”. Posdata n’2, 59-90.

NinO, C. (1991): Presidencialismo y estabilidad democrática en Argentina. Buenos Aires: CEI.

Nolte, D. (1995): "De La larga agonía de la Argentina Peronista a la Reconversión Menemista". En: HOFMEISTER, W. y THESING, J. (Edit.): Transformación de los sistemas políticos en América Latina. Buenos Aires: Konrad Adenauer Stiftung y CIEDLA.

Novaro, M. (1995): "Las funciones representativas del Parlamento Argentino". Cuadernos del CLAEH. n ${ }^{\circ}$ 73-74. $2^{\circ}$ serie, año 20, 179-186.

O’Donnell, G. (1990): "Delegative Democracies". East and South System Transformation Proyect. Budapest.

O’Donnell, G. (1995): “Otra Institucionalización”, Agora, $N^{\circ}$ 5, Invierno de 1995, 5-28.

O'Donnell, G. y Schmitter, P. (1986): Transiciones desde un gobierno autoritario. $\mathrm{n}^{\circ}$ 4. Buenos Aires: Paidós. 1991.

PÁSARA, L. (1993a): "El rol del parlamento: Argentina y Perú”. Desarrollo Económico. Vol. 32. Nº 128.

PÁsARA, L. (1993b): "La Crisis de los Partidos Políticos en Perú:¿Un caso excepcional?”. En: GARRETÓN M., M. A.: Los partidos y la transformación política de América Latina. Santiago: FLACSO-Chile.

Palmer, D.S. (1994): Shining Path of Perú. New York: St. Martin's Press. $2^{\mathrm{a}}$ edition Cap. 1.

Palmer, D. S. (1995): "Perú's Stacked Elections". En: The Christian Science Monitor, 7 de abril de 1995.

PlanAs, P .(1996): “¿Existe un sistema de partidos?”. En: Tuesta Soldevilla, F. (edit.): Los enigmas del poder. Fujimori 1990-1996. Lima: Fundación Friedrich Ebert.

Perelli, C., Picado, S. y Zovatto, D. (1995) (Comp.): Partidos y clase política en América Latina en los '90. San José: IIDH. CAPEL.

REYNoso, D. (1997): “¿Democracia rutinizada o consolidada? Elecciones y Partidos Políticos en Argentina y Perú". Annual Meeting of the New England Council of Latin American Studies, (NECLAS), Mont Holyoke College, South Hadley, Mass, Estados Unidos, 18 de octubre de 1997.

SAnborn, C. y PANFichi, A. (1996): "Fujimori y las raíces del neopopulismo”. En: Tuesta Soldevilla, F. (edit.): Los enigmas del poder. Fujimori 1990-1996. Lima: Fundación Friedrich Ebert.

SARTORI, G. (1994): Ingeniería Constitucional Comparada. México: Fondo de Cultura Económica.

SPEHAR, E. y Forti, A.(1995): "Los parlamentos y la consolidación democrática: de lo formal a lo sustantivo". Cuadernos del CLAEH, $\mathrm{n}^{\circ} 73-74,2^{\circ}$ serie, año 20, 113 119.

Strada SÁEnZ, G. (1994): "El menemismo y la consolidación democrática en la Argentina". En: PINTO, J. (Comp.): América Latina en la década de los '80. Buenos Aires: UBA.

Von Beyme, K. (1993): La clase política en el Estado de Partidos. Madrid: Alianza Universidad. 1995. 


\title{
RESUMEN
}

A partir de aquella premisa que sostiene que la presencia de valores y actitudes democráticas en los ciudadanos como en las élites políticas son importantes para el surgimiento, estabilidad y consolidación de un régimen democrático; la autora analiza las actitudes hacia la democracia de los diputados argentinos y peruanos. Con este objetivo presenta los datos resultantes de la investigación de "Élites Parlamentarias en América Latina" y a partir de ellos sugiere que las orientaciones hacia la democracia de los diputados argentinos se podrían considerar como más "democráticas" que la de los diputados peruanos.

\begin{abstract}
Based on the perspective that democratic values and orientations among citizens and elites are imporant for the rise, stability and consolidation of democratic regimes, Flavia Freidenberg analyses the attitudes towards democracy of Argentinian and Peruvian parliamentarians. With this purpose, Freidenberg analyses data from the Research on Parliamentarian Elites in Latin america, and shows that the democratic values of Argentinian parliamentarians are stronger than those of Peruvian.
\end{abstract}

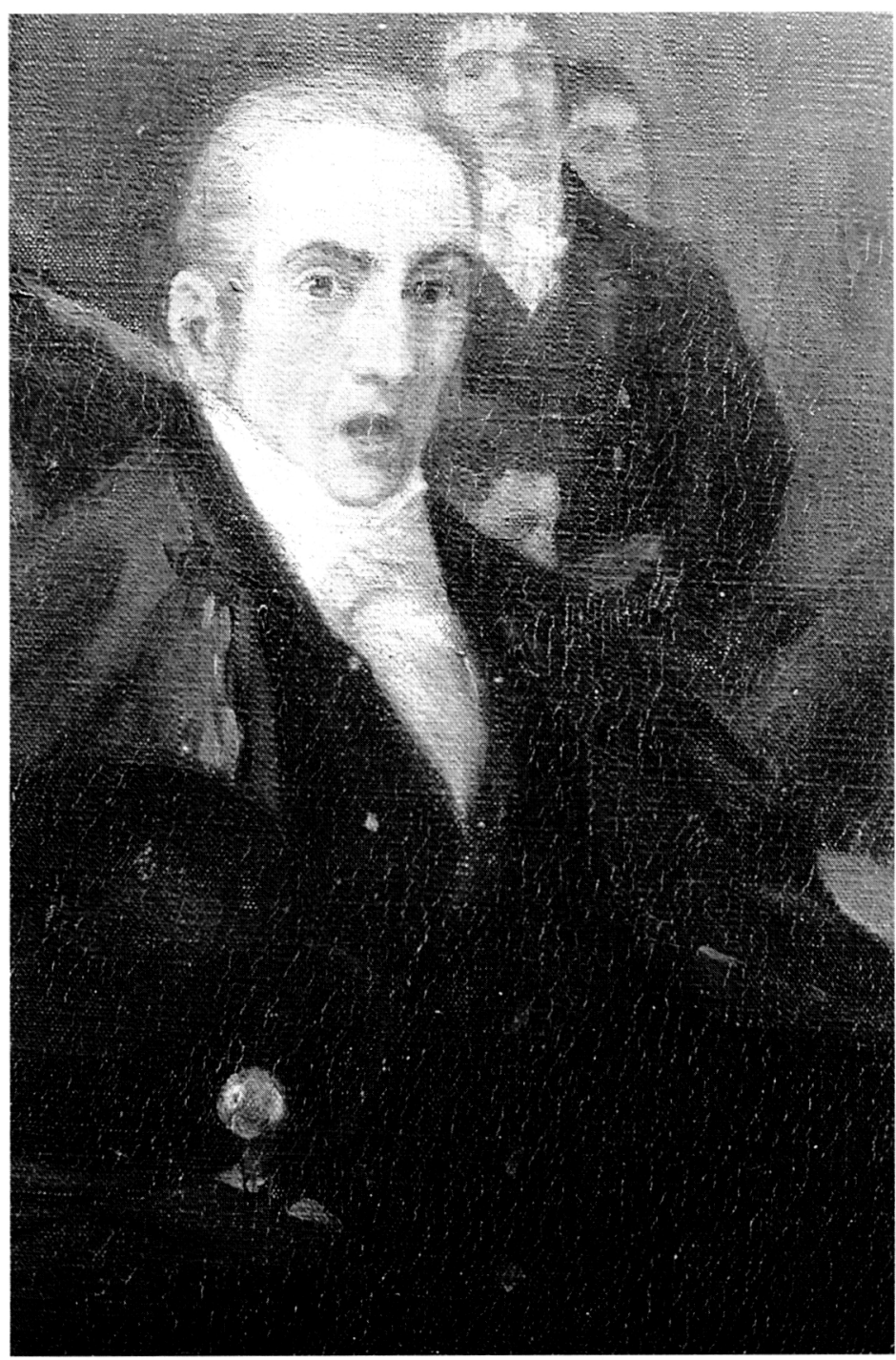

Cabildo Abierto 